Article

\title{
Probing the Highly Disparate Dual Inhibitory Mechanisms of Novel Quinazoline Derivatives against Mycobacterium tuberculosis Protein Kinases $A$ and $B$
}

\author{
Fisayo A. Olotu and Mahmoud E. Soliman * \\ Molecular Bio-Computation and Drug Design Laboratory, School of Health Sciences, \\ University of KwaZulu-Natal, Westville Campus, Durban 4001, South Africa; olotuf@ukzn.ac.za \\ * Correspondence: soliman@ukzn.ac.za; Tel.: +27-(0)-31-260-8048; Fax: +27-(0)-31-260-7872
}

Academic Editor: Giosuè Costa

Received: 19 May 2020; Accepted: 18 June 2020; Published: 16 September 2020

\begin{abstract}
Mycobacterium tuberculosis (Mtb) serine/threonine (Ser/Thr) Protein kinases A (PknA) and B $(\mathrm{PknB})$ have been identified as highly attractive targets for overcoming drug resistant tuberculosis. A recent lead series optimization study yielded compound 33 which exhibited potencies $\sim 1000$ times higher than compound 57. This huge discrepancy left us curious to investigate the mechanistic 'dual' (in)activities of the compound using computational methods, as carried out in this study. Findings revealed that 33 stabilized the PknA and B conformations and reduced their structural activities relative to 57. Optimal stability of 33 in the hydrophobic pockets further induced systemic alterations at the P-loops, catalytic loops, helix Cs and DFG motifs of PknA and B. Comparatively, 57 was more surface-bound with highly unstable motions. Furthermore, 33 demonstrated similar binding patterns in PknA and B, involving conserved residues of their binding pockets. Both $\pi$ and hydrogen interactions played crucial roles in the binding of 33, which altogether culminated in high $\Delta G_{s}$ for both proteins. On the contrary, the binding of 57 was characterized by unfavorable interactions with possible repulsive effects on its optimal dual binding to both proteins, as evidenced by the relatively lowered $\Delta G_{s}$. These findings would significantly contribute to the rational structure-based design of novel and highly selective dual inhibitors of $M t b$ PknA and B.
\end{abstract}

Keywords: Mycobacterium tuberculosis; multi-drug and extensively drug resistance; dual-targeting; serine/threonine protein kinases; structure-based design; medicinal chemistry

\section{Introduction}

The increase in the emergence of multi-drug and extensively drug resistant (MDR/XDR) Mycobacterium tuberculosis $(\mathrm{Mtb})$ strains represents a major setback to the treatment of tuberculosis, which is thereby still as a major global threat [1]. As reported, about two million new TB-related cases and deaths occur each year, in addition to a very worrisome approximately two billion latent infections [2]. Since the efficacies of existing anti-tubercular drugs have been thwarted by increasing incidences of drug resistance, there is the need for novel drugs that could disrupt crucial pro-resistance Mtb machinery.

In recent years, $M t b$ serine/threonine protein kinases (STPKs) have been pinpointed for their concerted involvement in mycobacterial viability [3,4]. This family of mycobacterial protein (11-membered) mediates protein phosphorylation events which play key roles in signal transduction to downstream pathways; typical of the two-component signaling cascade [5,6]. This underlies intracellular regulatory mechanisms by which the bacterium responds to extracellular signals and adapt to changes in environmental conditions. Usually, post-translational modifications such as 
phosphorylation, ubiquitination, and acetylation describe mechanisms by which $M t b$ responds to oxidative stress induced by external factors $[7,8]$.

Similar to eukaryotic kinases, STPKs possess extra cytoplasmic regions; to which extracellular molecules bind and intracellular kinase domains that phosphorylate a cohort of substrate proteins resulting in the activation of signaling cascades and eventual alterations in the expression of cellular biomolecules such as genes, proteins, lipids among others [5,6,9]. Members of the Mtb STPK family include protein kinases A-H, J-L; PknA, PknB, PknC, PknD, PknE, PknF, PknG, PknH, PknJ, PknK and PknL, which drive various microbial processes such cell wall synthesis, cellular growth, division, development, metabolism, and dormancy [5,10-13]. Most prominent among the STPK protein family are $\mathrm{PknA}$ and $\mathrm{PknB}$, which have been implicated in the regulation of cell wall synthesis, resuscitation from dormancy, transcription, translation, and other processes that strongly enhance adaptation to environmental stress, bacterial cell growth and division [9,14-20].

Protein kinases $\mathrm{A}$ and $\mathrm{B}$ are encoded by $p k n A$ and $p k n B$ genes, respectively, which are also located on the same operon containing genes that code for a Ser/Thr phosphatase $(p s t P)$, class B penicillin-binding protein $(p b p A)$ and candidate peptidoglycan (PG) synthase $(\operatorname{rod} A)$ [21,22]. PknA is made up an intracellular kinase domain that is connected to an extracellular domain via a juxtamembrane domain, likewise PknB which consists of an intracellular N-terminal and an extracellular C-terminal domain composed of four PASTA domains [23,24]. Crucial to the activity of these proteins are various structural elements that constitute their nucleotide binding regions such as the P-loop, catalytic loop, activation loop, helix C and the DFG motif. Helix C is located in the linker segment that connects the kinase homology domain to the transmembrane helix. The P-loop is a hexapeptide (PknA: 20-ATGGMG-25 and PknB: 18-GFGGMS-23) that coordinate phosphates via the main chain glycine amides [23]. The catalytic domain consists of the ATP binding site while the activation loop functions in the coordination of the Mg2+ or Mn2+ ion through specific inter-residual contacts [23,25]. Also contained in the activation loop are phosphorylated residues (PknA: A169, T172, T174, T176 and PknB: S166, S169, T171 and T173), although highly disordered [26]. Also, several structural features have been associated with the catalytic domain of these proteins with respect to ligand or substrate binding such as the tilting away of the helix C from the active site or the DFG out or in conformations [27-30].

The significance of $M t b P k n A$ has been attributed to its role in the mechanics and regulation of $M t b$ cellular shape as supported by its upregulation during the exponential growth and infection phases of the mycobacteria [31]. Moreover, its autonomous activation enhances in vitro growth and survival relative to its phosphorylative effects on downstream proteins involved in cell division, peptidoglycan, and mycolic acid synthesis [32,33].

The crucial role attributed to $M t b P \mathrm{knB}$ centers on its ability to enhance and sustain mycobacterial growth $[4,34]$. Also, its essential involvement in the reactivation of mycobacterial cells from the hypoxic state has been previously reported [13]. More so, Ser/Thr phosphorylation of proteins such as GarA regulatory protein, MabA, KasB, and InhA informs the ability of PknB to regulate $M t b$ central carbon metabolism and mycolic acid synthesis [15,35-38].

Moreover, PknA and PknB have been proposed as attractive therapeutic targets for inhibiting both active and latent forms of tuberculosis $[13,26]$. This is due to their critical involvement in sustaining bacterial growth as experimented in culture medium and host macrophages infected with $M t b[10,12,14,23,39,40]$. Interestingly, these proteins have less than $30 \%$ similarity with eukaryotic kinases in primary amino acid sequences presenting an avenue for achieving selective therapeutic targeting over human host kinases [23,28].

Although numerous research efforts have been directed towards inhibiting either of these proteins, a recent paradigm shift has been aimed at the development of dual selective inhibitors that can simultaneously target both proteins $[4,8,26,34,41,42]$. This therapeutic approach presents an avenue to minimize the rate at which resistance occurs while at the same time increasing specificity. In a recent study, Tiansheng and co-workers [26] synthesized a series of quinazoline derivatives with varying degrees of inhibitory potencies against protein kinases 
A and B. Significant among these series was the dually selective compound 5-(6-chloro-4-((5cyclopropyl-1H-pyrazol-3-yl)amino)quinazolin-2-yl)thiophene-2-sulfonamide (33) with Ki values $<8 \mathrm{nM}$ and $<1 \mathrm{nM}$ for PknA and PknB, respectively [26]. This compound exhibited the highest inhibitory activity and selectivity compared to other derivatives (Figure 1). Interestingly, a chemical analog, (4-(5-cyclopropyl-1-methyl-1H-pyrazol-3-ylamino)-5-methylpyrimidin-2yl)thiophene-2-sulfonamide (57) [5], exhibited poor selectivity and inhibitory potency against these kinases ( $\mathrm{Ki}>4000 \mathrm{nM})$. It is therefore expedient to understand the mechanisms by which chemical substitutions on these derivatives mediate significantly disparate selective and inhibitory activities on $M t b$ PknA and PknB.

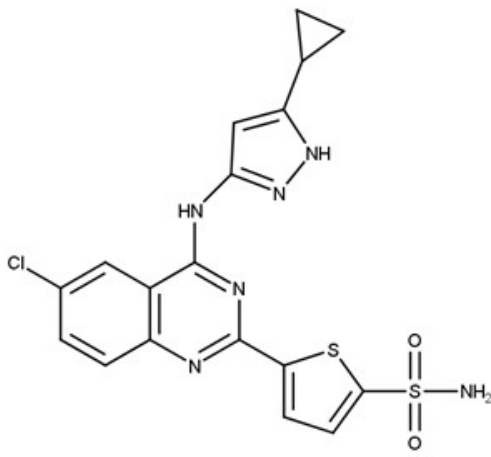

33

$$
K_{\text {iPknA }}=<8(\mathrm{nM})
$$

$K_{\text {ipknB }}=<1(\mathrm{nM})$

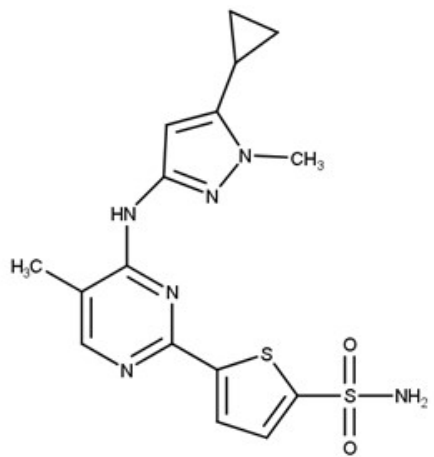

57

$$
\begin{aligned}
& K_{i \text { knA }}=>4000(\mathrm{nM}) \\
& K_{i \text { knB }}=>4000(\mathrm{nM})
\end{aligned}
$$

Figure 1. Chemical structures of $M t b$ Ser/Thr Protein kinases A and B inhibitors with their experimentally reported $K_{i}$ values.

Herein, we implemented qualitative GPU-accelerated molecular dynamics (MD) simulations, binding free-energy calculations and free energy decomposition analysis to: (i) probe the dynamics of selectivity and non-selectivity elicited by 33 and 57, respectively, towards PknA and PknB; (ii) investigate the ligand-induced dynamics of the alternative hinge binding region and (iii) study how chemical substitutions influence the binding affinities of both compounds. To achieve this, we prepared and studied six protein systems: unbound PknA, unbound PknB, 33-bound PknA, 33-bound PknB, 57-bound $\mathrm{PknA}$ and 57-bound PknB. The respective compounds were bound to the nucleotide binding pockets of the proteins which were defined in line in previous crystallographic studies [26,42]. This region consists of various structural elements as earlier mentioned which exhibits various conformational variations with respect to the binding of substrates or small molecular compounds.

We expect that rational insights from this study would enhance further lead optimization that could open up avenues for the discovery of novel compounds with improved selectivity and dual inhibitory potencies against PknA and B in anti-TB therapies.

\section{Results and Discussion}

\subsection{Conformational Stability and Ligand-Induced Variations}

Structural arrangements of a protein play a critical role in its biological functionalities. Also, the ability of small-molecule compounds to mediate dual selective inhibition of protein homologs could be enhanced or limited by the nature of the respective target sites. Moreover, structural insights into binding site architectures could provide a rational explanation for the mechanistic activities of small therapeutic molecules which could also enhance the structure-based design of novel chemical entities.

Structural and sequential disparities among bacterial kinases of the STPK family have been widely described, which underlies our focus on the conformational dynamics of PknA and PknB, particularly the catalytic domains (nucleotide binding pockets), relative to the binding of 33 and 57 . 
This presents an approach to understand how the selective inhibitory activities of the compounds varied from PknA to PknB as reported by Wang et al. [26].

Firstly, we employed the RMSD metrics to enumerate the stability of the studied systems, which could be deduced from motions of the constituent $C \alpha$ atoms across the simulated trajectories.

From the resulting plots (Figure 2A,B), we observed that the systems seemingly converged with minimal deviations at about 170 ns with conformational RMSDs $<2 \AA$. Then, the finally equilibrated RMSD (FE-RMSD) of the proteins' backbone $\mathrm{C} \alpha$ atoms were defined from the terminal 30ns where minimal $\mathrm{C} \alpha$ motions were observed across the systems. These post-equilibrated time frames were also employed for subsequent analyses.

Results are presented in Figure 2C,D, and from our findings, we predict that structural fluctuations may follow the 57-PknA $>$ 57-PknB $>33-\mathrm{PknA}>33-\mathrm{PknB}$ order, a presumption that would be subsequently investigated using other methods (metrics). Interestingly, estimated mean values, as reported in Table 1 may correlate with experimental bioactivity data and showed that the lowest FE-RMSD value was obtained for 33-bound PknB which reportedly had the better $K i$ value. Further FE-RMSD estimations revealed that the unbound proteins ( $\mathrm{PknA}$ and $\mathrm{PknB}$ ) demonstrated high structural deviations relative to their ligand-bound forms (Supplementary Figure S1).

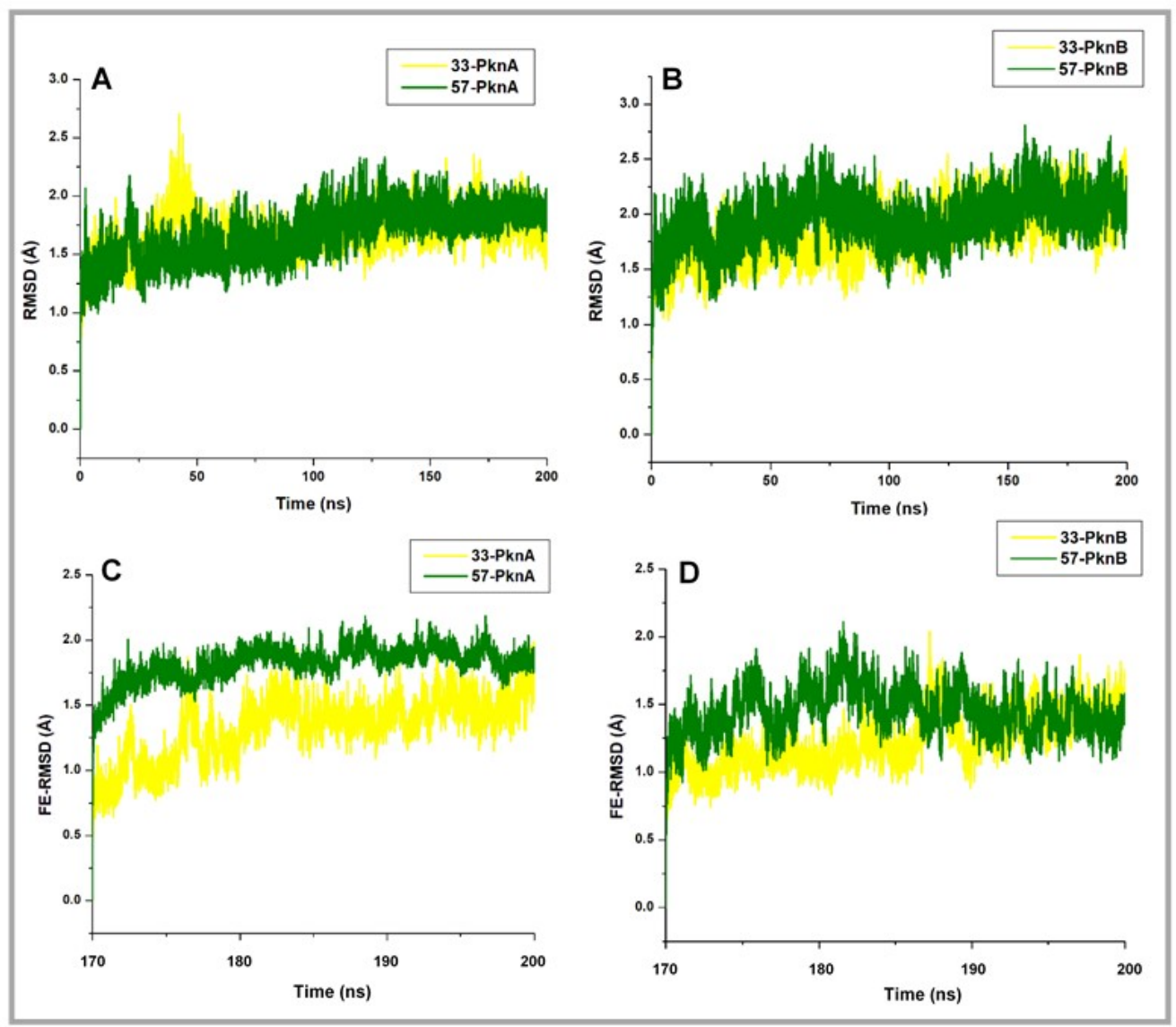

Figure 2. RMSD plots showing variations across the entire PknA and PknB structures as induced by the binding of 33 and 57. Finally equilibrated RMSD (FE-RMSD) plots estimating minimal C $\alpha$ deviations for the ultimate 30 ns time frames are also shown. (A) Whole structure RMSD plot for 33and 57-bound PknA (B) Whole structure RMSD plot for 33- and 57-bound PknB (C) FE-RMSD plots for 33- and 57-bound PknA (D) FE-RMSD plots for 33- and 57-bound PknB. 
Table 1. Conformational analysis of protein kinases A and B complexed with compounds 33 and 57. Estimated $K_{i}$ value is also indicated.

\begin{tabular}{ccccccc}
\hline Post Equilibration & PknA & 33-PknA & 57-PknA & PknB & 33-PknB & 57-PknB \\
\hline \multicolumn{7}{c}{ Whole Structure } \\
\hline Whole RMSD & $2.42 \pm 0.16$ & $1.40 \pm 0.2$ & $1.14 \pm 0.11$ & $2.01 \pm 0.30$ & $1.39 \pm 0.25$ & $1.44 \pm 0.19$ \\
\hline FE-RMSD $(\AA)$ & $2.38 \pm 0.35$ & $1.33 \pm 0.23$ & $1.82 \pm 0.13$ & $1.95 \pm 0.29$ & $1.24 \pm 0.20$ & $1.45 \pm 0.18$ \\
\hline FE-RMSF $(\AA)$ & $1.41 \pm 0.69$ & $0.89 \pm 0.40$ & $1.00 \pm 0.42$ & $1.11 \pm 0.34$ & $0.79 \pm 0.46$ & $1.05 \pm 0.55$ \\
\hline$K_{i}(n M)[26]$ & $<8$ & $>4000$ & $<1$ & $>4000$ \\
\hline FE-RMSD $(\AA)$ & $2.31 \pm 0.31$ & $1.51 \pm 0.17$ & $2.00 \pm 0.23$ & $2.42 \pm 0.11$ & $1.59 \pm 0.26$ & $2.34 \pm 0.43$ \\
\hline FE-RoG $(\AA)$ & $13.10 \pm 0.28$ & $9.27 \pm 0.13$ & $10.26 \pm 0.11$ & $12.34 \pm 0.03$ & $8.54 \pm 0.09$ & $11.93 \pm 0.14$ \\
\hline
\end{tabular}

Also, hydrogen bond (HB) analyses were performed to further determine the stability of the studied systems with respect to ligand binding (Supplementary Figure S2). Considering the overall systems, findings revealed that average HB increased in the presence of the compounds, with a higher proportion in the 33-bound proteins. Estimated HBs were 149, 143, 132 and 126 respectively for 33-PknB, 33-PknA, 57-PknA, 57-PknB complexes. Higher HB counts associated with the 33-bound complexes could deduce an increase in the stability of the proteins [43,44]. Relatively, reduced average HBs (PknA $=122, \mathrm{PknB}=123)$ in the unbound proteins could possibly indicate an increase in structural flexibility or instability $[43,45]$.

In addition, $\mathrm{HB}$ interactions with occupancies $\geq 90 \%$ were selected from the ultimate $30 \mathrm{~ns}$ trajectories (170-200 ns) and compared among the systems to gain further clues into the relative stabilities of the proteins (Supplementary Table S1). As presented, $7 \mathrm{HBs}$ had occupancies $>90 \%$ in unbound PknA, and 5 in unbound PknB, which increased to 14 (33-PknA), 15 (33-PknB) and 10 (57-PknA and B). These additional HBs may account for the stability of the proteins at these ultimate time frames. Taken together, we can suggest that the binding of compounds $\mathbf{3 3}$ and $\mathbf{5 7}$ stabilized the overall proteins' structure relative to their unbound forms.

Furthermore, using the post-equilibrated time frames (final $30 \mathrm{~ns}$ ), we enumerated the degree of atomistic deviations induced differentially by the compounds at the NBPs of the proteins. Our findings revealed that the binding of 57 induced alterations in the structural arrangements of both PknA and B NBPs while the pockets were more stable in the presence of 33 (Figure 3). Estimated average RMSD values are also presented in Table 1 . Hence, we could suggest that the dual binding of $\mathbf{3 3}$ to both proteins reduced residual mobility the active site regions as well, compared to compound $\mathbf{5 7}$. These structural effects, as caused by $\mathbf{3 3}$, could be as a result of high-affinity interactions with certain active site components, as elucidated in subsequent sections. In addition, the NBPs of unbound PknA and PknB demonstrated higher deviations which could suggest high mobility among constituent residues (structural components) relative to their catalytic activities.

To gain further insights into the systemic alterations induced by the compounds, we employed the $\mathrm{C} \alpha$ RMSF metrics which is able to determine the extent of fluctuation of individual amino acid residues over the MD simulation period. We estimated the final equilibrated RMSF (FE-RMSF) depictive of the post-equilibrated trajectories. FE-RMSF analysis revealed higher structural fluctuations for 57-bound PknA and PknB compared to minimal fluctuations exhibited both proteins when bound by 33 (Figure 4D,E). From the estimations, FE-RMSF was decreased in the 33-bound proteins compared to the relatively higher values obtained for those bound by compound 57 (Table 1). This corroborates the FE-RMSD data which further implies that the ligand activities with respect to structural fluctuation were in the 57-PknA $>57-\mathrm{PknB}>33-\mathrm{PknA}>33-\mathrm{PknB}$ order. This means that the least fluctuation occurred in the 33-bound PknB while structural fluctuation was higher in the 57-bound proteins. This could be correlated with the experimental data which revealed that 33 was most active in 
PknB. Also, residual fluctuations were relatively higher in the unbound proteins compared to the ligand-bound systems.
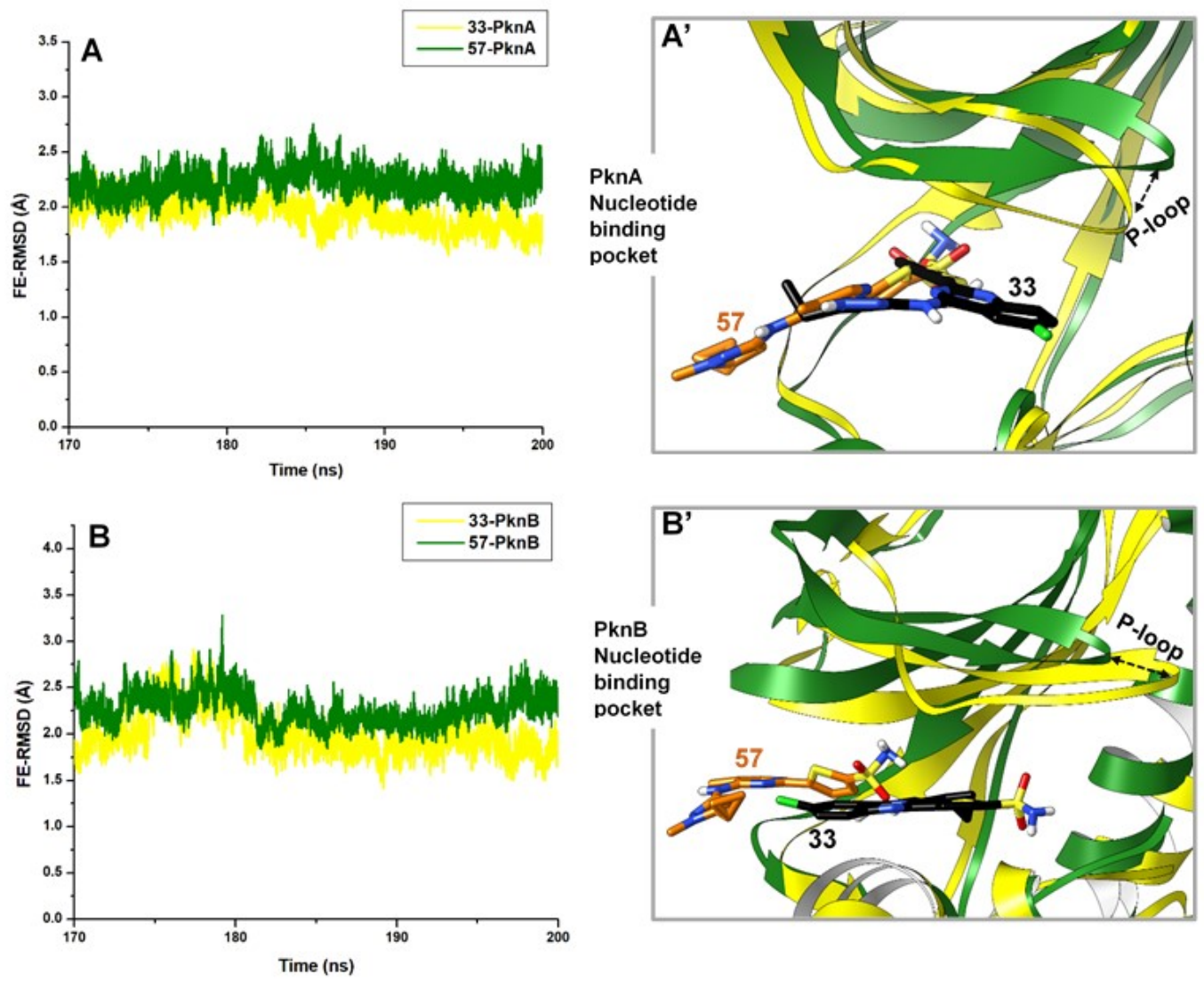

Figure 3. FE-RMSD plot showing systematic $C \alpha$ deviations as induced by 33 and 57 at the nucleotide binding pockets of (A). PknA and (B). PknB. Orientations of the compounds with respect to their binding activities are shown in $\left(\mathbf{A}^{\prime}, \mathbf{B}^{\prime}\right)$. Also captured are the alterations at the NBP P-loop induced by the binding of compound 33 .

We further mapped out specific structural elements of both proteins; P-loop, helix C, DFG motifs and catalytic loops, since they are important to substrate binding and protein functionality $[25,46,47]$. The results, as presented in Table 2, revealed that the binding of 33 to PknA decreased motions at the helix C, catalytic loop and DFG motif. Also, motions were relatively reduced at the P-loop, catalytic loop and DFG motif by 33 in PknB. According to 3D-visualization of the structurally superposed 33- and 57-bound proteins, we observed that the P-loop, catalytic loop and, DFG-motif regions were extended into the active pocket in the presence of $\mathbf{3 3}$ with slight alterations in the helix $\mathrm{C}$ regions (Figure $4 \mathrm{~B}, \mathrm{C}$ ).

Table 2. RMSF analysis of structural components of the PknA and PknB NBPs in the presence of compounds 33 and 57.

\begin{tabular}{ccccccc}
\hline & \multicolumn{7}{c}{ Structural Fluctuation $(\AA)$} \\
\hline Structural Components & PknA & 33-PknA & 57-PknA & PknB & 33-PknB & 57-PknB \\
\hline P-loop & $2.36 \pm 0.25$ & $1.50 \pm 0.36$ & $1.46 \pm 0.36$ & $2.14 \pm 0.14$ & $0.92 \pm 0.22$ & $1.14 \pm 0.37$ \\
\hline Helix C & $1.59 \pm 0.51$ & $1.11 \pm 0.30$ & $1.35 \pm 0.50$ & $1.52 \pm 0.43$ & $0.88 \pm 0.32$ & $1.48 \pm 0.57$ \\
\hline Catalytic loop & $0.88 \pm 0.10$ & $0.70 \pm 0.12$ & $0.71 \pm 0.13$ & $0.69 \pm 0.06$ & $0.48 \pm 0.04$ & $0.66 \pm 0.22$ \\
\hline DFG-motif & $1.41 \pm 0.14$ & $0.55 \pm 0.02$ & $0.72 \pm 0.10$ & $1.01 \pm 0.04$ & $0.48 \pm 0.02$ & $0.92 \pm 0.05$ \\
\hline
\end{tabular}


These variations in motions could be as a result of complementary ligand interactions with constituent residues as earlier mentioned. These binding dynamics would be discussed in subsequent sections. Comparatively, differences in the motions of these structural components relative to their unbound forms could be predictive of the degree to which they were altered with respect to ligand binding (Table 2 and Supplementary Figure S3). Accordingly, we could deduce that ligand binding induced a measure of structural rigidity among these components compared to the unbound forms. Also, between the 33- and 57-bound systems, we observed that less fluctuation were observed in the Helix C, catalytic loop and the DFG-motif which could indicate the ability of compound 33 to disrupt the catalytic activity of these kinases more potently.

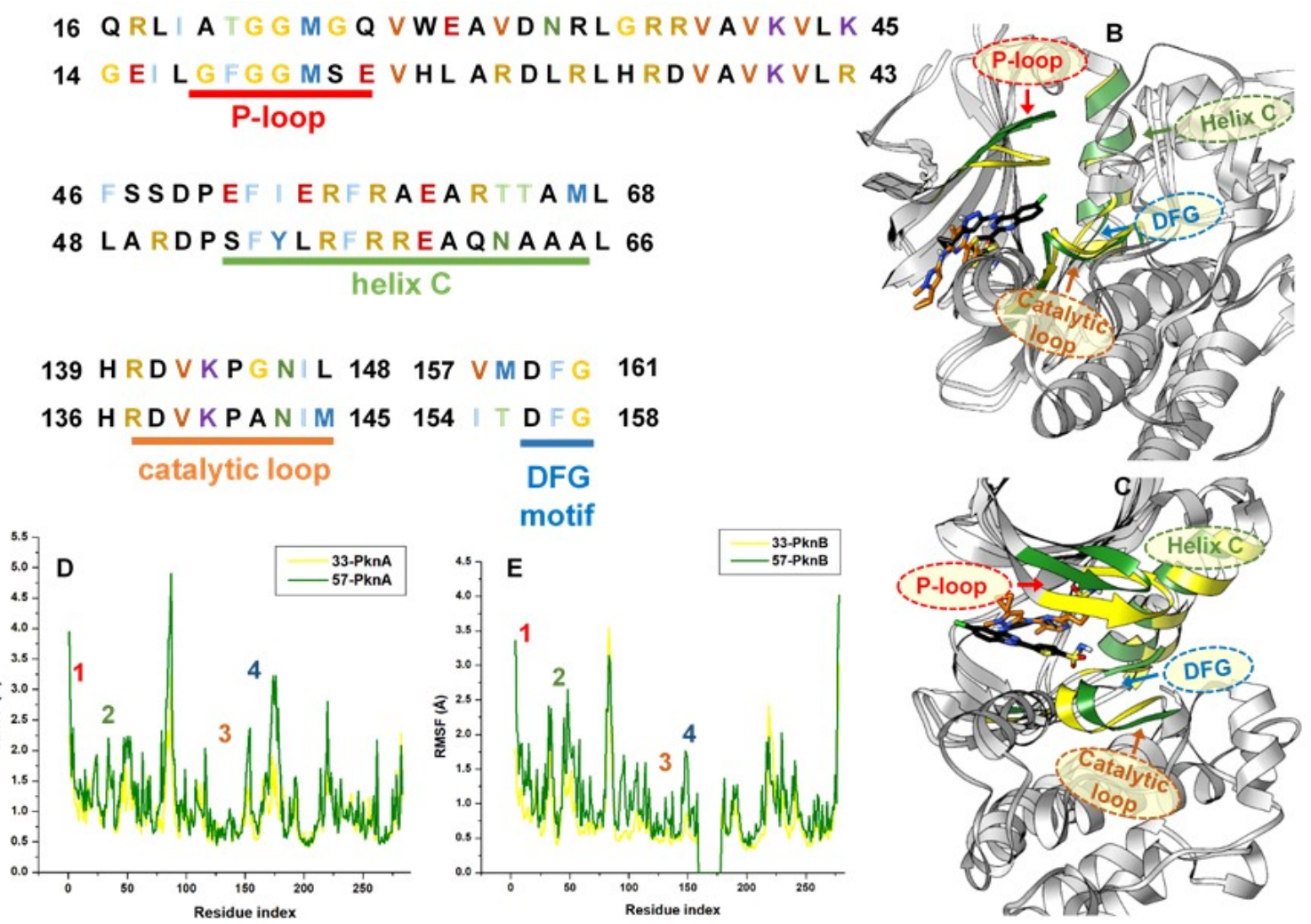

Figure 4. RMSF plots showing per-residual fluctuations across key components of PknA and PknB structures. (A) Sequence alignment of the NBP region of both proteins showing variations in constituent residues. Highlighted are the various residue sequences that encompass the P-loop (red), helix C (green), catalytic loop (brown) and DFG motif (blue). These regions are color-indicated on the RMSF plot in (D,E) (1 = P-loop, 2 = helix C, 3 = catalytic loop, 4 = DFG motif). 3D structural alignment of 33(black) and 57- (orange) bound PknA and PknB are shown respectively in (B,C).

Another important observation from Figure 3 was the surface-binding exhibited by compound 57 while 33 was bound deeply within the NBP of both proteins. These binding attributes exhibited by 57 could reduce its binding affinity since it is unable to access the deep pocket region of both proteins.

We further estimated differential compactness of PknA and PknB NBPs (nucleotide binding pockets) in the presence of both compounds using the equilibrated radius of gyration (FE-RoG) metrics. This was employed herein to measure how the binding of compounds $\mathbf{3 3}$ and 57 alter the compactness of PknA and B active pockets and also corroborate variations among the various catalytic components as earlier estimated. RoG has been widely employed as a parameter to determine the compactness of protein systems which in turn could be used to suggest the structural stability (or mobility) of such systems [48]. It measures atomic distribution from the center of mass, hence a high RoG could correlate with high structural instability or motion and vice versa [49]. From the estimations, high mobility 
characterizes the unbound NBPs of PknA and B, as supported by their relatively high FE-RoG values (Supplementary Figure S1). However, the active pockets of PknA and B appeared to be more compact (less motions) in the presence of 33 relative to 57. Prominent reductions in variations, as induced by $\mathbf{3 3}$, could be due to alterations among constituent structural elements such as the P-loop, catalytic loop, and DFG-motif as shown in Figure 5. FE-RoG between 33- and 57-bound PknA-NBP varied by $0.99 \AA$ while a difference of $3.39 \AA$ was pertinent to 33- and 57-bound PknB-NBP (Table 1). These estimations could further reflect the dual bioactivity of $\mathbf{3 3}$ against $\mathrm{PknA}$ and $\mathrm{PknB}$ as experimentally reported.
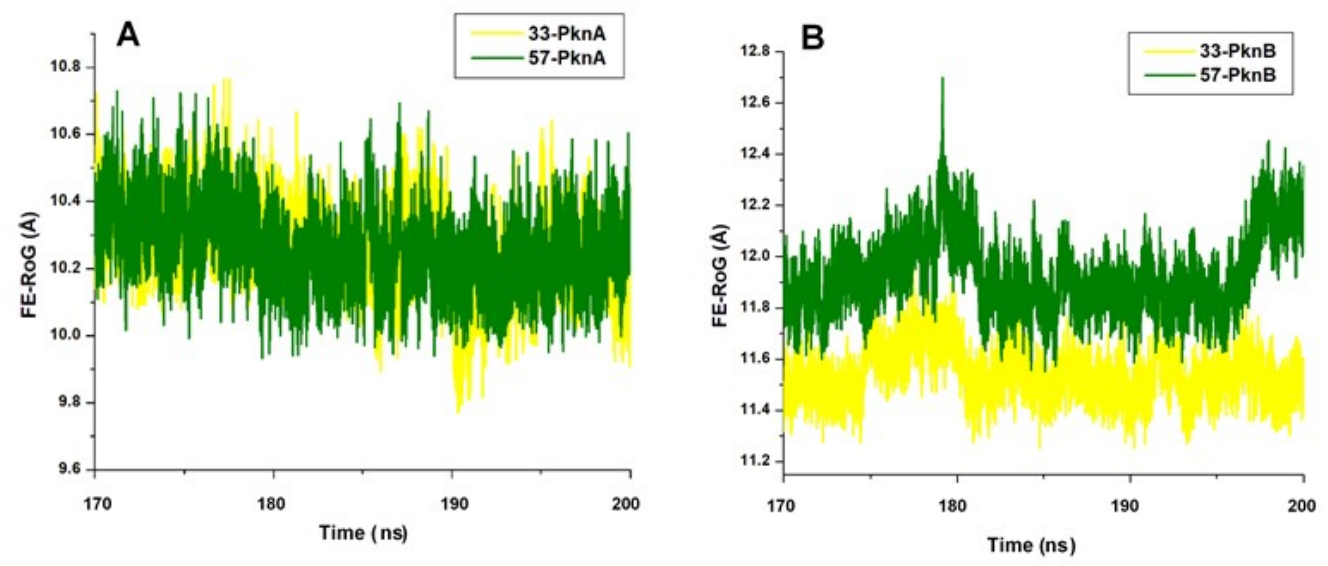

Figure 5. C $\alpha$ RoG plot showing the degree of structural compactness at the NBP of (A) PknA-bound 33 and 57 (B) PknB-bound 33 and 57.

\subsection{Dynamic Cross Correlation Matrix (DCCM)}

The disparate $\mathrm{C} \alpha$ motions occurring among constituent residues of $\mathrm{PknA}$ and $\mathrm{PknB}$ when bound differentially by 33 and 57 were further described using the DCCM parameter. This analysis could also provide dynamical insights into the directions of residual motions along the MD simulation time frames. Resulting matrices are presented in Figure 6. Yellow to deep red colors depict positively correlated motions and cyan to black colors represent motions that are negatively correlated or anticorrelated. As shown, highly correlated motions occurred in unbound PknA while moderate $\rightarrow$ deep $\rightarrow$ negatively correlated motions (Supplementary Figure S2) were observed in unbound PknB, indicating high fluctuations and possibly, inter-residual interactions among constituent residues. Narrowing down, key structural components of their catalytic sites such as the P-loop, helix C and catalytic loop showed high correlations (PknA and B) which was reduced in the DFG motif of PknB (residues 156-158). Overall, highly correlated motions demonstrated by the unbound proteins could suggest their high elasticity or flexibility, a conformation that may be essential for their catalytic activities.

On the contrary, anti-correlated motions were increased in the presence of the compounds which could imply that their binding interfered with residual fluctuations, particularly at regions that constitute the NBPs of the proteins. Suggestively, this reduction in mobility could indicate restraints imposed by ligand binding. Comparatively, more correlated motions characterized the 57-bound proteins as compared to the 33-complexes which had more anticorrelated residual motions. Structural components of the NBPs were mapped out to further indicate the degree to which they were differentially altered by the ligands (Supplementary Figure S3C,D). As seen, anticorrelations were more enhanced in PknA around the P-loop, helix C, catalytic loop and DFG motif when bound by compound 33 while the DFG motif was more correlated in 33-PknB.

Moreover, since positive motions could indicate outward residual motions and vice versa [50], we could further indicate that the 33-bound proteins were more stable in line with earlier RMSD and RMSF results. Likewise, we could suggest that the reduction in structural flexibilities of PknA and $\mathrm{B}$, particularly the NBP, was induced by the ligands, since they appeared to be highly flexible in the unbound forms. 

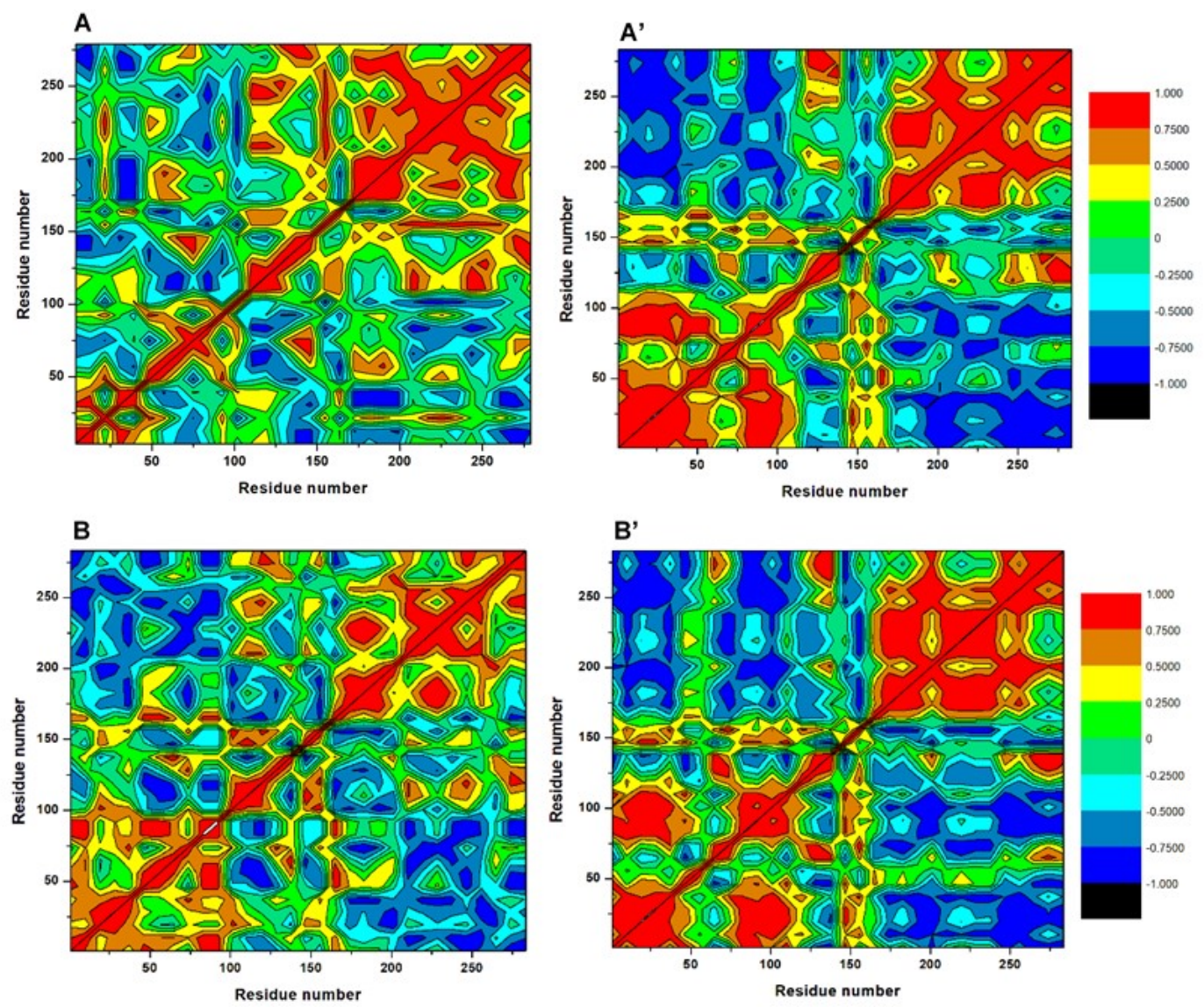

Figure 6. Dynamic cross-correlation matrices of the Ca fluctuations in the ultimate 30 ns simulation period (A) 33-bound PknA, (A') 57-bound PknA (B) 33-bound PknB and (B') 57-bound PknB.

\subsection{Systematic Analyses of Binding Dynamics to Understand Differential Inhibitory Mechanisms}

We further probed the mechanisms by which both compounds mediated dual (in)activities against PknA and PknB over the entire MD simulation period. 3D conformations of the 33- and 57-bound complexes were retrieved from the resulting trajectories and subjected to comparative time-based analysis. The starting structures were the pre-MD 33- and 57-bound complexes and as observed the structural components were aligned with no alterations occurring yet. Based on our findings, a disparate fluctuation was observed, majorly at the P-loop region of PknA when differentially bound by 33 and 57.

As shown in Figure 7, a steady downward pull of the P-loop region characterized the binding of compound 33 across the simulation periods. This was also accompanied by movements in the DFG motif, catalytic loop and helix $C$ regions. These structural variations were also observed across the post-equilibrated time frames (170-200 ns). Consequentially, these motions (inward pulling effects) could complement the compactness of the NBP which in turn favored ligand stability. Comparatively, time-based structural analyses of the unbound $\mathrm{PknA}$ and $\mathrm{B}$ proteins revealed minimal variations among these components over the simulation period, particularly at the post-equilibrated trajectories (Supplementary Figure S4). 

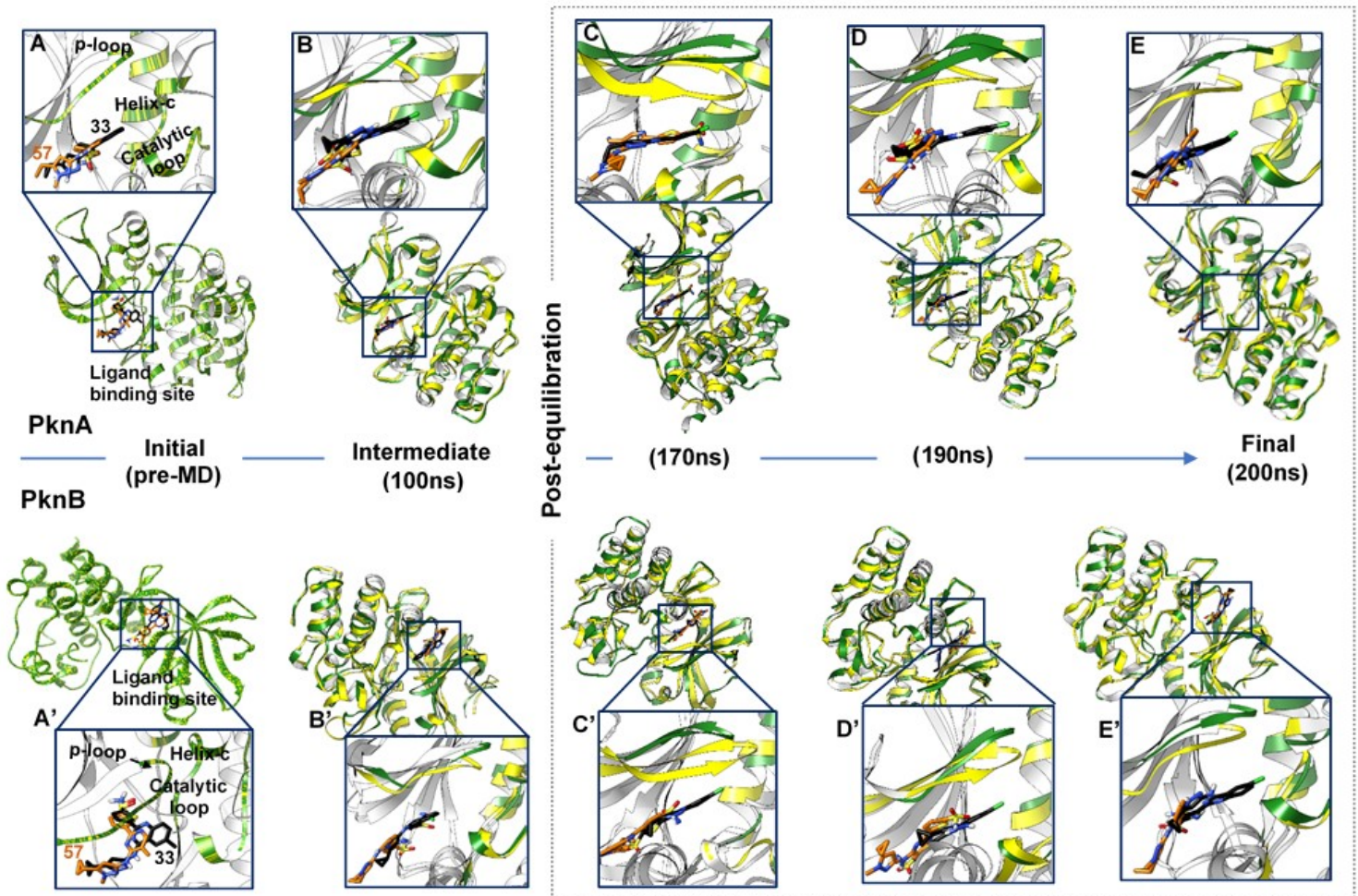

Figure 7. Comparative analyses of systemic alterations induced by the binding activities of compounds 33 (black) and 57 (orange) in PknA- and PknB-NBPs at different time-frames of the simulation run starting from their pre-MD complexes where no alterations in catalytic components occurred yet. Relative motions of PknA P-loop, catalytic loop and helix C regions are revealed in (A-E) from the pre-simulation to the post-equilibrated timeframes while relative alterations in $\mathrm{PknB}$ catalytic domain are showed in $\left(\mathbf{A}^{\prime}-\mathbf{E}^{\prime}\right)$. Orientations of the compounds were also shown along the trajectories.

An in-depth look at the interaction mechanisms of 33 revealed key residues that contributed to high-affinity and stable binding, as analyzed from the terminal (post-equilibrated) time frames. These include GLY22 $\left(\rightarrow\right.$ GLY20 $\left.{ }_{\mathrm{PknB}}\right)$, LYS42 $\left(\rightarrow \mathrm{LYS40}_{\mathrm{PknB}}\right)$, GLU96 $\left(\rightarrow\right.$ GLU93 $\left.{ }_{\mathrm{PknB}}\right)$, VAL98 $\left(\rightarrow\right.$ VAL95 $\left._{\text {PknB }}\right)$, LYS143 $\left(\rightarrow\right.$ LYS140 $\left._{\text {PknB }}\right)$, THR158 $\left(\rightarrow\right.$ MET155 $\left._{\text {PknB }}\right)$ and ASP159 $\left(\rightarrow\right.$ ASP156 $\left.6_{\text {PknB }}\right)$ (Figure 8). GLY22 is located at the P-loop region, and its amide- $\pi\left(n \rightarrow \pi^{*} \mathrm{Ar}\right)$ interaction could contribute notably to the stability of compound 33 . The importance of this interaction with respect to the stability of small molecules has been previously reported [51]. Another important interaction observed was a high-affinity H-bond between the quinazoline ring of $\mathbf{3 3}$ and LYS42; one of the conserved catalytic residues of Ser/Thr kinases. This also could have played a crucial role in the stability of the compound. The terminal sulfonamide oxygen atom $\left(\mathrm{O}_{1}\right)$ of compound 33, as well, elicited conventional $(\mathrm{NH}-\mathrm{O})$ bond with VAL98 while an NH-O bond occurred between the carbonyl oxygen of GLU96 and terminal hydrogen $\left(\mathrm{H}_{14}\right)$ of the compound. Moreover, these $\mathrm{H}$-bonds have distances between 1.9-2.5 $\AA$, indicative of their strengths and stabilities. 
Ser/Thr Protein kinase A - Nucleotide binding pocket
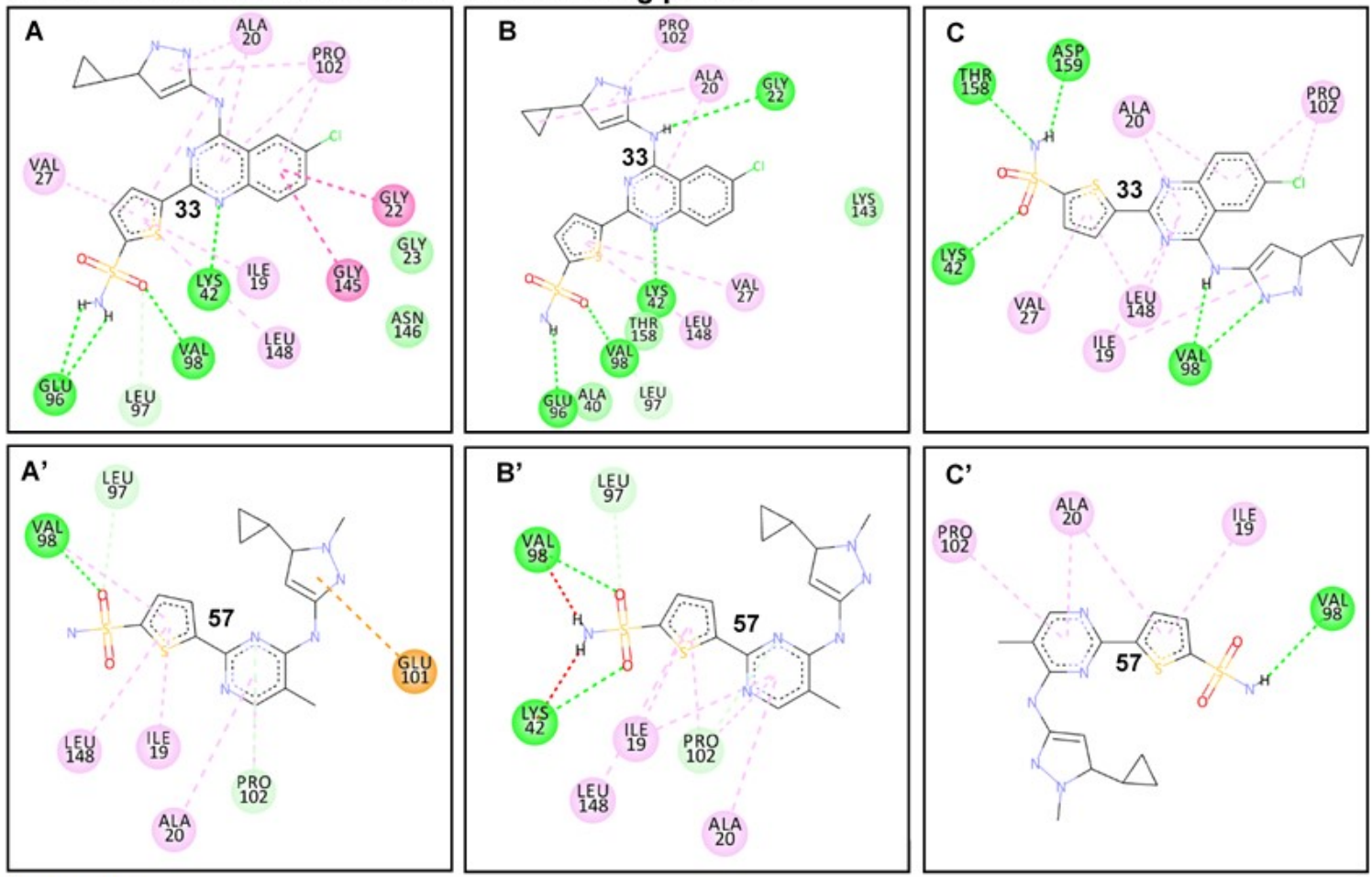

B'
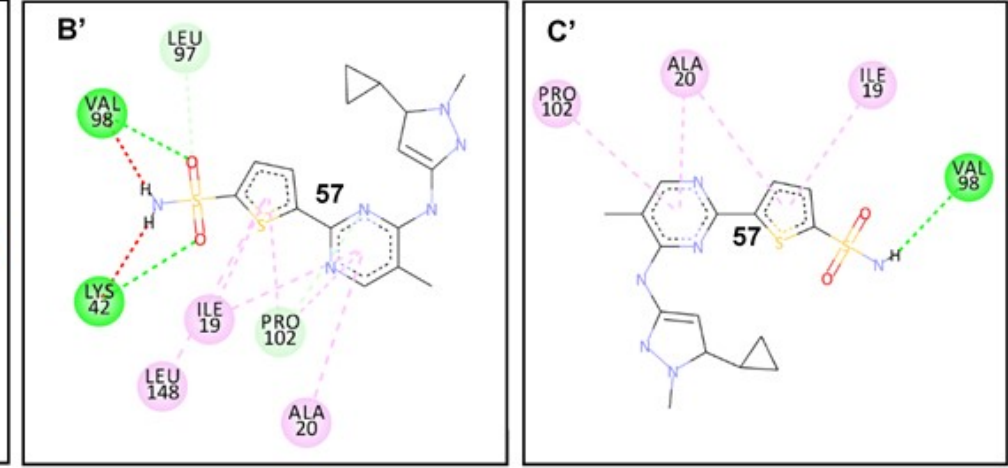

Interactions

van der Waals

Alkyl

Unfavorable Donor-Donor

Pi-Pi Stacked

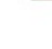

Pi-Anion

Pi-Alkyl

Figure 8. Comparative binding dynamics of compounds 33 and 57 at the NBP of PknA across post-equilibrated trajectories 170-200ns (A) 33-PknA at $170 \mathrm{ns.} \mathrm{(B)} \mathrm{33-PknA} \mathrm{at} 190 \mathrm{~ns}$ (C) 33-PknA

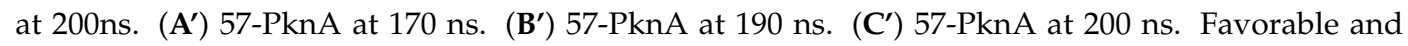
unfavorable interactions that characterize the binding of the ligands are shown and are well represented by their respective legends.

Conventional H-bond interactions elicited by THR158 and ASP159 with the sulfonamide group of 33 further contributed to its high-affinity binding stability at the active pocket. The occurrence of these interactions at the final time frames of simulation could suggest that the sulfonamide moiety was optimally displaced away from GLU96 and VAL98 which are located at the entrance of the NBP. This could indicate that compound 33 was more favorably oriented deep into the pocket for a more stable binding (see Figure $3 \mathrm{~A}^{\prime}, \mathrm{B}^{\prime}$ above).

Also observed is the intermittent carbon hydrogen bond $(\mathrm{CH}-\mathrm{Cl})$ between the constituent $\mathrm{Cl}$ atom of compound 33 and LYS143 (catalytic loop), which could also contribute in part to the stability of the compound. This interaction was however lost in 57-PknA due to the $\mathrm{Cl} \rightarrow \mathrm{CH}_{3}$ substitution. Additionally, residues such as ALA20, VAL27, PRO102 AND LEU148 interacted via $\pi$-alkyl interactions while LEU97 coordinately interacted with the sulfonic oxygen atom $\left(\mathrm{O}_{1}\right)$ of 33 .

These interactions occurred at the pyrazole and thiophene rings of the compound. In all, three residues of the P-loop; ALA20, GLY22, and VAL27 engaged in complementary interactions with compound 33 which could possibly explain the downward pull motions exhibited by the P-loop over the simulation period (see Figure 7).

For PknB, conventional hydrogen bonds characterized the binding of compound 33 in addition to a high number of aromatic $(\pi)$ interactions. 33 interacted with PHE19, GLU93, and VAL95 via high-affinity NH-O bonds while LYS140 and ASN143 engaged with the terminal sulfonic O atoms of 33 (Figure 9). The $\pi$ interactions could also play important roles in the stability of the compound 
since they occurred with the constituent thiophene, pyrazole, and quinazoline rings. On the contrary, 57 exhibited different interaction mechanisms that could possibly explain its inhibitory inactivities towards PknA and PknB. At the initial time frame (post-equilibrated - $170 \mathrm{~ns}$ ), we observed that weak pi-alkyl interactions were more prominent in addition to minimal conventional $\mathrm{H}$-bonds $(\mathrm{NH}-\mathrm{O})$ with VAL98 AND GLU96.

\section{Ser/Thr Protein kinase B - Nucleotide binding pocket}
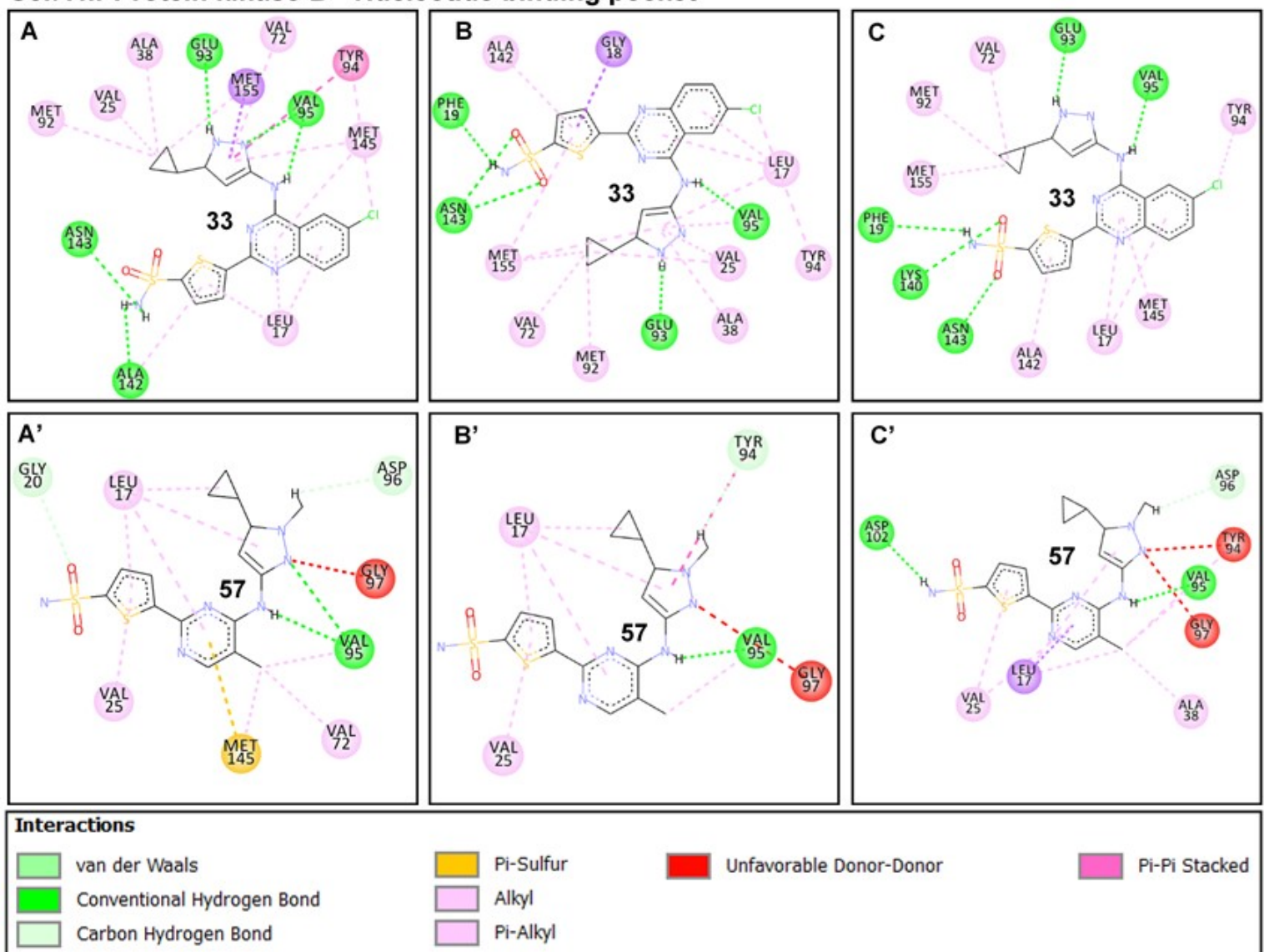

Figure 9. Binding dynamics of compounds 33 and 57 at the NBP of PknB as estimated from the post-equilibrated time frames 170-200 ns. (A) 33-PknB at $170 \mathrm{~ns}$. (B) 33-PknB at $190 \mathrm{~ns}$. (C) 33-PknB

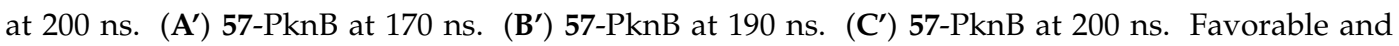
non-favorable interactions involved disparately in the binding of $\mathbf{3 3}$ and $\mathbf{5 7}$ are indicated. Appropriate legends representing each interaction types are also shown.

An important highlight of the 57-PknA complex was the occurrence of unfavorable donor-donor $(\mathrm{NH}-\mathrm{HN})$ interactions with VAL98 and LYS42, indicative of an unfavorable and unstable binding pattern. These unfavorable interactions could affect its binding at the deep hydrophobic region of the NBP of both proteins which could, in turn, explain its surface-binding as observed in Figure 3. Moreover, these interactions were intermittent and reduced at the final frame where scantly weak interactions were observed. Although 57 engaged in $\mathrm{NH}-\mathrm{O}$ interactions with the carbonyl oxygen of PknB-VAL95 (VAL98 in PknA), unfavorable interactions occurred with TYR94 and GLY97 via its constituent pyrazole ring. Taken together, we could deduce that the occurrence of unfavorable interactions could underlie repulsive electrostatic effects on the binding of 57 at the NBPs of PknA and PknB.

The differential stability and positioning of the compounds at the active pockets were further examined by the PCA and SASA values since the latter parameter is sufficient to predict the degree to which the compounds are exposed to the surrounding solvent [52]. We clustered the ligand motions 
along two principal components; PC1 and PC2 and observed that 57 demonstrated a more dispersed motion at the NBPs while a more compact motion was demonstrated by 33 (Figure 10). This further implies that compound 33 had a more stable binding compared to 57 . The unstable pattern of motion exhibited by 57 could suggest its inability to maintain high-affinity interactions with crucial residues at the NBP, hence the gradual loss in interaction as shown in Figure $8 A^{\prime}-C^{\prime}$ and Figure $9 A^{\prime}-C^{\prime}$.
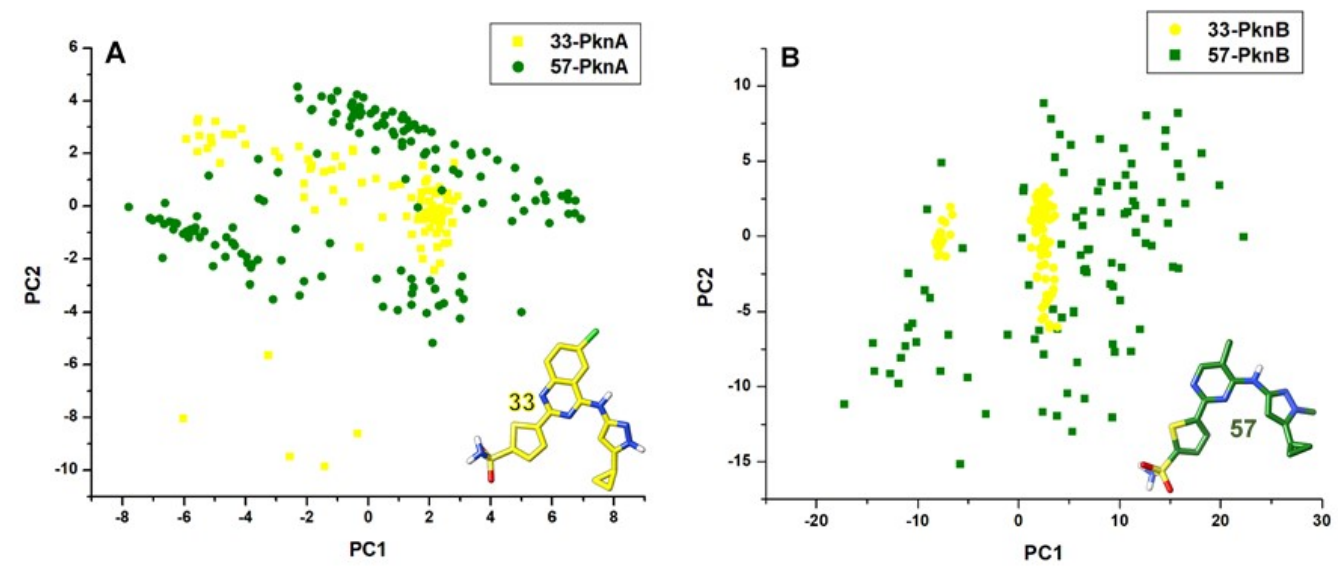

Figure 10. Principal component analyses of the differential motions of compounds 33 and 57 at the nucleotide binding pockets of (A) PknA and (B) PknB over the simulation period. Depicted in yellow and green colorations are compounds 33 and 57 respectively.

Compounds 33 and 57 were then masked to further investigate their motions at the solvent phases and results revealed that 33 exhibited lower solvent motions indicative of its deep hydrophobic motions compared to 57 with high SASA peaks that could indicate its highly unstable and surface- motion, corroborative of findings earlier mentioned. Mean SASA values for 33 were $74.7 \AA^{2}$ and $61.9 \AA^{2}$ in PknA, while 146.2 $\AA^{2}$ and 101.2 $\AA^{2}$ were estimated for 57 in PknB. This corroborates findings presented in Figure $3 \mathrm{~A}^{\prime}$ and $3 \mathrm{~B}^{\prime}$ which showed that 33 was more deeply bound in the hydrophobic pockets of PknA and PknB while 57 was surface-bound, outside the NBP. Taken together, we could deduce from our findings that the highly unstable dynamics exhibited by $\mathbf{5 7}$ could account for its inability to bind dually and proximally at the NBPs of both PknA and B. This, in turn, could rationally explain its highly reduced affinity as experimentally reported.

\subsection{Estimation of Binding Affinities and Per-Residue Energy Decomposition}

The MM/GBSA-based approach was further used to estimate the differential binding of both compounds while the energy contributions of interacting residues were also determined. Findings are presented in Table 3. From our calculations, binding free energy $\left(\Delta G_{\text {bind }}\right)$ increased from 33 to 57 by -25.72 $\mathrm{kcal} \mathrm{mol}^{-1}$ in PknA and $-29.04 \mathrm{kcal} \mathrm{mol}^{-1}$ in PknB. This further reflects the experimentally reported data in which 33 exhibited more favorable binding to both proteins compared to 57. More so, entropical effects were minimal on the total binding energies and as shown, van der Waals (vdW) and electrostatic interactions in the gas phase were more favorable for $\mathbf{3 3}$ with a relative reduction for $\mathbf{5 7 .}$ Also, we can deduce that, relative to electrostatic effects, vdW energies contributed more towards the binding and stability of 33 in both proteins. This could be, in part, due to the prominent $\pi$ interactions earlier reported. 
Table 3. Binding free energy profiling of 33- and 57- PknA and PknB complexes.

\begin{tabular}{ccccc}
\hline \multicolumn{5}{c}{ Binding Free Energy Analysis } \\
\hline Energy Components (kcal mol-1) & 33-PknA & $\mathbf{5 7 - P k n A}$ & 33-PknB & 57-PknB \\
\hline$\Delta$ EvdW & $-46.38 \pm 0.18$ & $-28.25 \pm 0.10$ & $-51.02 \pm 0.12$ & $-29.79 \pm 0.11$ \\
$\Delta$ Eele & $-24.64 \pm 0.22$ & $-11.18 \pm 0.08$ & $-29.15 \pm 0.19$ & $-24.99 \pm 0.42$ \\
$\Delta$ Ggas & $-71.02 \pm 0.26$ & $-39.43 \pm 0.10$ & $-80.17 \pm 0.20$ & $-54.78 \pm 0.83$ \\
$\Delta$ Gele,sol(GB) & $28.36 \pm 0.13$ & $29.89 \pm 0.05$ & $31.70 \pm 0.13$ & $35.26 \pm 0.45$ \\
$\Delta$ Gnp,sol & $-5.85 \pm 0.01$ & $-3.0 \pm 0.01$ & $-6.26 \pm 0.01$ & $-5.57 \pm 0.07$ \\
$\Delta$ Gsol & $22.51 \pm 0.13$ & $26.89 \pm 0.05$ & $25.44 \pm 0.13$ & $29.99 \pm 0.39$ \\
$\Delta H$ & $-48.51 \pm 0.16$ & $-12.54 \pm 0.06$ & $-54.73 \pm 0.14$ & $-24.79 \pm 0.52$ \\
$T \Delta S$ & $-2.76 \pm 0.08$ & $-7.46 \pm 0.03$ & $-4.73 \pm 0.06$ & $-3.89 \pm 0.26$ \\
$\Delta G$ bind & $-45.75 \pm 0.24$ & $-20.03 \pm 0.15$ & $-50.0 \pm 0.14$ & $-20.9 \pm 0.15$ \\
$K i(n M)$ & $<8$ & $>4000$ & $<1$ & $>4000$ \\
\hline
\end{tabular}

In addition, desolvation effects accounted for unfavorable polar $\left(\Delta G_{\text {ele,sol(GB) }}\right)$ and total polar solvation energies $\left(\Delta G_{\mathrm{sol}}\right)$. These could imply that the binding of compound $\mathbf{3 3}$ was more favorable in the active pocket relative to 57 as indicated by its estimated $\left(\Delta G_{\text {ele,sol(GB) }}\right)$ and $\left(\Delta G_{\text {sol }}\right)$ values. These corroborate the non-polar $\left(\Delta G_{n p, s o l}\right)$ energies derived from the burial of the ligand away from the solvent accessible region. $\Delta G_{n p \text {,sol }}$ values were more favorable for 33 compared to 57 , which could imply that the former was more deeply bound in the hydrophobic pocket regions of both proteins.

Comparatively, electrostatic energies increased by $-13.46 \mathrm{kcal} \mathrm{mol}^{-1}$ between 33 - and 57 -bound PknAs while vdW contributions varied by $-18.13 \mathrm{kcal} \mathrm{mol}^{-1}$. Also, in PknB, electrostatic and van der Waals energies differ by $-4.16 \mathrm{kcal} \mathrm{mol}^{-1}$ and $-21.23 \mathrm{kcal} \mathrm{mol}^{-1}$ respectively. This further emphasizes the importance of van der Waals contributions to the high-affinity binding and stability of $\mathbf{3 3}$ in

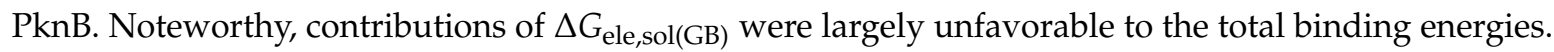
This could suggest that electrostatic interactions associated with ligand motions at the active site may not be strong enough to compensate fully for the huge desolvation penalties that characterized ligand binding. Comparatively, we observed a huge decrease in net electrostatic interactions to $-4.23 \mathrm{kcal} \mathrm{mol}^{-1}$ in PknA and $0.28 \mathrm{kcal} \mathrm{mol}^{-1}$ in PknB. Presumably, complementary vdW contributions were sufficient to influence the dual inhibitory activities of 33 .

Binding free energies were further decomposed using the MM/GBSA method to identify crucial residues and their respective energy contributions to the disparate binding of both inhibitors. Per-residue interactions with energy contributions exceeding the $-1 \mathrm{kcal} \mathrm{mol}^{-1}$ threshold were considered favorable [53]. Corresponding energy plots of interacting residues (within $5 \AA$ radius) are shown in Figures 11 and 12. In 33-PknA; ILE19, GLY22, MET95, LEU97, VAL98, ASN99, PRO102, LEU148, THR158 and ASP159 showed energy contributions $>-1 \mathrm{kcal} \mathrm{mol}^{-1}$, hence their presumed prominence towards the overall $\Delta G_{\text {bind }}$ of compound 33. These energies were decreased in the 57PknA with a majority of them falling below the $-1 \mathrm{kcal} \mathrm{mol}^{-1}$ threshold. The crucial roles played by these residues via complementary hydrogen and aromatic interactions with the ligands (as earlier explained) are reflected by their energy contributions.

vdW energies from ILE19, GLY22, VAL27, MET95, LEU97 and LEU148 decreased from 33-PknA to $57-\mathrm{PknA}$ by $-0.74,-1.09,-1.14,-1.15,-1.27$ and $-1.23 \mathrm{kcal} \mathrm{mol}^{-1}$ respectively. Moreover, we could deduce that high involvement of aromatic interactions could contribute favorably to the high vdW energies estimated for the 33-bound systems. Also, high vdW $\left(-1.08 \mathrm{kcal} \mathrm{mol}^{-1}\right)$ and electrostatic $\left(-1.66 \mathrm{kcal} \mathrm{mol}^{-1}\right)$ energies were contributed by VAL98 to the binding of 33 , which reduced by $-0.2 \mathrm{kcal} \mathrm{mol}^{-1}(\mathrm{vdW})$ and $-1.56 \mathrm{kcal} \mathrm{mol}^{-1}$ (electrostatic) in 57-PknA. This could rationally explain the mechanistic loss of affinity exhibited by $\mathbf{5 7}$. More so, PRO102 favored the binding of both $\mathbf{3 3}$ and $\mathbf{5 7}$ to PknA but energetically unfavorable contributions by $\operatorname{ASP159}\left(\Delta E_{\text {ele }}=2.30 \mathrm{kcal} \mathrm{mol}^{-1}\right)$ could exert negative effects on the overall $\Delta G_{b i n d}$ of 57 .

Comparatively, while vdW energetic contributions to $33\left(>-1 \mathrm{kcal} \mathrm{mol}^{-1}\right)$ added up to $-13.05 \mathrm{kcal} \mathrm{mol}^{-1}$, the sum of electrostatic energies equaled $-16.24 \mathrm{kcal} \mathrm{mol}^{-1}$, which was compensated 
to $-10.71 \mathrm{kcal} \mathrm{mol}^{-1}$ by cumulative effects of unfavorable polar electrostatic effects $\left(\Delta G_{\text {ele,sol(GB) }}\right)$. This further indicates that the binding and stability of $\mathbf{3 3}$ in PknA was also dependent on vdW forces with terms mainly associated with the occurrence of complementary $\pi$ interactions. Noteworthy, unfavorable polar energies for 57 added up to $11.75 \mathrm{kcal} \mathrm{mol}^{-1}$, which drastically reduced occurring electrostatic effects $\left(>-1 \mathrm{kcal} \mathrm{mol}^{-1}\right)$ to $8.02 \mathrm{kcal} \mathrm{mol}^{-1}$. This provides additional clue into the unfavorable binding of 57 to PknA.

Further decomposition of energies between 33- and 57-bound PknBs, revealed a PknA-similar pattern of energetic contributions by the interacting residues. Residues such as LEU17 ( $\rightarrow$ ILE19PknA), GLY18 $\left(\rightarrow\right.$ ALA20 $\left.{ }_{\text {PknA }}\right)$, PHE19 $\left(\rightarrow\right.$ THR21 $\left.{ }_{\text {PknA }}\right)$, GLY20 $\left(\rightarrow\right.$ GLY22 $\left.{ }_{\text {PknA }}\right)$, VAL25 $\left(\rightarrow\right.$ VAL27 $\left.{ }_{\text {PknA }}\right)$, MET92 $\left(\rightarrow\right.$ MET95 $\left.{ }_{\text {PknA }}\right)$, GLU93 $\left(\rightarrow\right.$ GLU96 $\left._{\text {PknA }}\right)$, TYR94 $\left(\rightarrow\right.$ LEU97 $\left._{\text {PknA }}\right)$, VAL95 $\left(\rightarrow\right.$ VAL98 $\left._{\text {PknA }}\right)$, ASN143 $(\rightarrow$ ASN146 PknA $)$, MET145 $(\rightarrow$ LEU148 PknA $)$ and MET155 $\left(\rightarrow\right.$ THR158 $\left.{ }_{\text {PknA }}\right)$ contributed highly favorable energies $\left(>-1 \mathrm{kcal} \mathrm{mol}^{-1}\right.$ ) to the binding and stability of 33. Comparatively, respective energy decreases of $-1.48,-0.72,-0.98,-0.75,-1.74,-0.62,-1.97,-1.79,-2.89,-1.14,-0.12$ and $-1.23 \mathrm{kcal} \mathrm{mol}^{-1}$ were estimated for these same residues in the $57-\mathrm{PknB}$ complex. Highest total energetic contributions to 33 in PknB were mediated by LEU17 $\left(-2.95 \mathrm{kcal} \mathrm{mol}^{-1}\right)$ and VAL95 $\left(-2.96 \mathrm{kcal} \mathrm{mol}^{-1}\right)$. Strong hydrogen bonds from VAL95 underlies its high vdW contributions while $\mathrm{vdW}$ energies from LEU17 $\mathrm{PknB}$ emanates from aromatic $\pi$ alkyl interactions with which it coordinates the thiophene and quinazoline ring of 33 (Figure 9). Common to the binding of $\mathbf{3 3}$ and $\mathbf{5 7}$ is the unfavorable energy contributions by D102 which may arise from steric effects. As seen in Figure 11D, their sulfonamide Os seem to orient towards an O group in D102, although at different distances (closest in 33). These orientations may elicit unfavorable O-O interactions, which would however be compensated for by other favorable energies relatively high in the 33-bound complex.

Correlative residues in PknA; ILE19 AND VAL98 (conserved), had similar high energy values of -2.40 and $-1.08 \mathrm{kcal} \mathrm{mol}^{-1}$ respectively. Therefore, we could deduce that 33 interacted similarly with key active site residues, although stronger in $\mathrm{PknB}$, which could account for higher affinity according to experimental data. Favorable vdW contributions to the binding and stability of 33 in PknB summed up to $-17.60 \mathrm{kcal} \mathrm{mol}^{-1}$ which were cumulatively decreased to $-7.28 \mathrm{kcal} \mathrm{mol}^{-1}$ in the presence of 57 . Highest vdW contributions to 33 were mediated by LEU17 $\left(-3.40 \mathrm{kcal} \mathrm{mol}^{-1}\right)$ and MET155 (-2.51 kcal mol${ }^{-1}$ ) with reductions to $-1.60 \mathrm{kcal} \mathrm{mol}^{-1}$ and $-1.319 \mathrm{kcal} \mathrm{mol}^{-1}$ in the presence of 57 .

High electrostatic contributions of $-5.35,-3.86,-2.64,-1.15$ and $-1.00 \mathrm{kcal} \mathrm{mol}^{-1}$ were contributed by GLU93 $\left(\rightarrow\right.$ GLU96 $\left._{\text {PknA }}\right)$, VAL95 $(\rightarrow$ VAL98 PknA $)$, LYS140 $\rightarrow$ LYS143 $\left._{\text {PknA }}\right)$, TYR94 $\left(\rightarrow\right.$ LEU97 $\left._{\text {PknA }}\right)$ and ASP138 $(\rightarrow \mathrm{ASP141}$ PknA ) respectively, bringing the favorable energy (electrostatic) contributions to $-14.00 \mathrm{kcal} \mathrm{mol}^{-1}$ (Figure 12). On the contrary, in 57-PknB, electrostatic energy contributions by these residues were reduced to $-1.40 \mathrm{kcal} \mathrm{mol}^{-1}$ (GLU93), 0.15 (VAL95), -0.72 (LYS140), -0.06 (TYR94) and -0.36 (ASP138). This notable difference could further support the superior binding affinity exerted by 33 to PknB relative to compound 57. High electrostatic terms of GLU93 could have been partly due to its strong H-bond interactions while $\pi$ interactions with the aromatic ring of TYR94 correlate with its high electrostatic contributions to 33 . Polar solvation terms were unfavorably $\left(>1 \mathrm{kcal} \mathrm{mol}^{-1}\right.$ ) high in 57 with a total $\Delta G_{\text {ele,sol(GB) }}$ sum of $11.05 \mathrm{kcal} \mathrm{mol}^{-1}$ which was reduced to $7.17 \mathrm{kcal} \mathrm{mol}^{-1}$ in 33. While compensatory effects render the total electrostatic contributions to 57 unfavorable $\left(4.55 \mathrm{kcal} \mathrm{mol}^{-1}\right)$, electrostatic contributions to 33 decreases to $-6.83 \mathrm{kcal} \mathrm{mol}^{-1}$, further indicating the importance of the vdW contributions to the active site affinity and stability of 33 in PknB. 

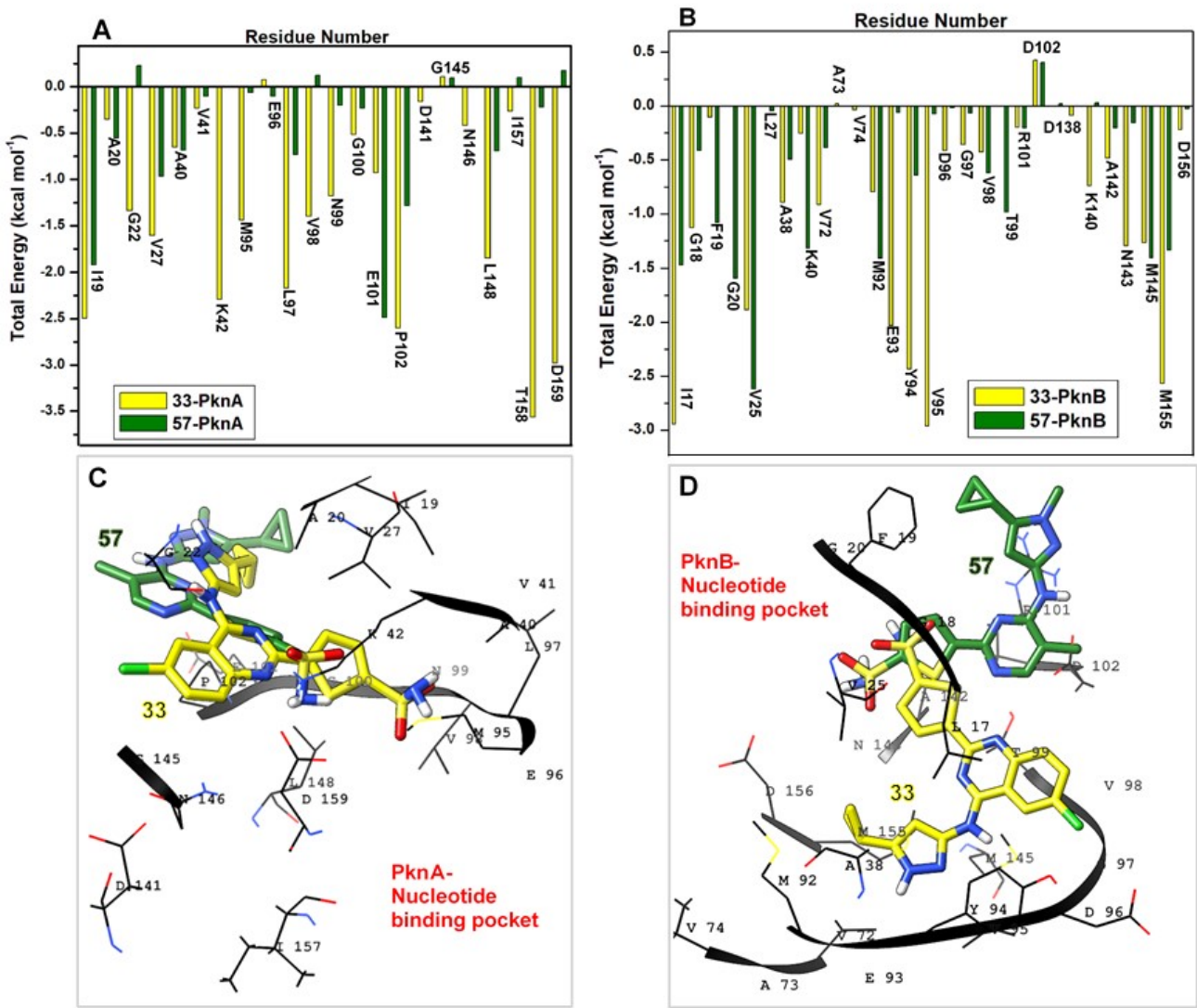

Figure 11. Total energy contributions of important catalytic residues to the differential binding and stabilities of compounds 33 and 57 at the nucleotide binding pockets of $\mathrm{PknA}$ and $\mathrm{PknB}$. (A) Comparative energies of catalytic residues to 33 and 57 in PknA (B) Comparative energies of catalytic residues to 33 and 57 in $\mathrm{PknB}$ (C) Structural representation showing the positioning of $\mathbf{3 3}$ and $\mathbf{5 7}$ relative to the NBP residues in PknA (D) Structural representation showing the positioning of $\mathbf{3 3}$ and $\mathbf{5 7}$ relative to the NBP residues in PknB.
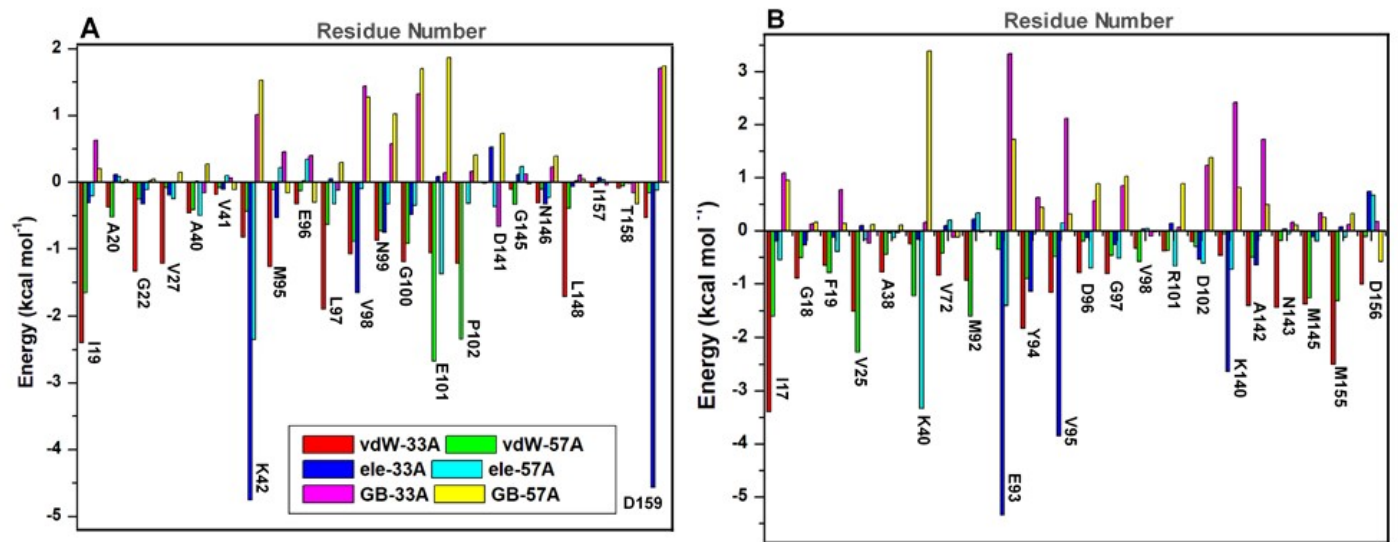

Figure 12. Energy $\left(\Delta G_{b i n d}\right)$ decomposition on a per-residue basis into contributions from the van der Waals, electrostatic and polar solvation $\left(\Delta \mathrm{G}_{\text {ele,sol }(\mathrm{GB})}\right)$ energies for crucial NBP residues. (A) $\Delta G_{\text {bind }}$ per-residue energy contributions of catalytic components in PknA nucleotide binding pocket (B) Per-residue energy contributions of catalytic components in PknB nucleotide binding pocket. Appropriate legends depicting the contribution type and protein system are shown likewise. vdW—van der Waals; ele-electrostatic; GB-polar solvation $\left(\Delta \mathrm{G}_{\text {ele,sol (GB) }}\right)$. 
Taken together, the dual binding of 33 to PknA and PknB was cumulatively favored by van der Waals and electrostatic contributions from key core residues (conserved and non-conserved) at the hydrophobic NBPs of both proteins. On the other hand, unfavorable interactions drastically reduced the dual binding affinities of $\mathbf{5 7}$ at the protein binding pockets.

\section{Computational Methods}

\subsection{Preparation of Ligand and Protein Starting Structures}

The crystal structures of PknA and PknB were obtained from the RCSB Protein Data Bank (PDB) with entries 6B2Q and 6B2P respectively [26]. The retrieved structures were prepared by removing co-crystallized molecules not relevant to this study using UCSF Chimera software version 1.11.2. However, prior to the removal of co-crystallized compounds, three-dimensional $(x, y, z)$ grid boxes were set to define corresponding coordinates correlative to active site regions (nucleotide binding pockets) in both proteins. This was necessary to ensure 33 and 57 were docked in the appropriate regions relative to the crystallized complexes. 2D structures of compounds 33 and 57 were prepared on MarvinSketch GUI while full energy optimization and minimization were done at the B3LYP/6-311++G(d,p) level using the Gaussian16 program package [54]. This was essential in order to obtain the most stable conformations for docking simulations.

\subsection{Docking and MD Simulations}

Optimized structures of 33 and 57 were respectively docked into the binding regions of $P \mathrm{knA}$ and PknB using the UCSF Chimera-integrated Vina module. Prior to docking simulations, we ensured that the selected binding regions in both proteins entailed residues located within a $5.0 \AA$ radius of the co-crystallized compounds. This was essential so as not to omit residues that might be crucially involved in ligand activity. Ten conformations were generated for each inhibitor and the best were preferentially selected based on their structural alignment with the co-crystallized compounds. This was to ensure that the co-crystallized ligand conformations were selected as initial structures for inhibitors $\mathbf{3 3}$ and 57 at the respective binding regions. Based on crystal orientations, 33-PknA, 33-PknB, 57-PknA and 57-PnkB complexes were selected as the docking-predicted models for MD simulations.

We performed long-timescale MD simulations using the Graphic Processor Unit (GPU) version of Amber18 together with its integrated modules [55]. Parameters were defined for the protein using the FF14SB forcefield while antechamber and parmchk modules were used to generate parameter files for the compounds. In order to define coordinate and topology files for the ligand-protein complexes, we executed the LEAP program, which also simultaneously performed system neutralization (by addition of counter $\mathrm{Na}+$ and $\mathrm{Cl}-$ ions) and explicit solvation in a $10 \AA$ sized TIP3P water box. Initial minimization was performed for 2500 steps using a $500 \mathrm{kcal} \mathrm{mol}^{-1}$. $\AA^{2}$ restraint potential after which a full minimization was carried out for 10000 steps with no restraints. The systems were then heated in a canonical (NVT) ensemble with a $5 \mathrm{kcal} \mathrm{mol}^{-1} \AA^{2}$ harmonic restraint from 0-300 K for 50 ps with the aid of a Langevin thermostat [56]. This was followed by the equilibration step in an NPT ensemble for 1000 ps without restrains at a temperature of $300 \mathrm{~K}$ while the Berendsen barostat was used to maintain the pressure at 1bar [57]. The production run lasted for a period of $200 \mathrm{~ns}$ for each protein in their unbound and ligand-bound forms. These altogether consists of 6 systems: unbound $\mathrm{PknA}$, unbound $\mathrm{PknB}, 33-\mathrm{PknA}, 33-\mathrm{PknB}, 57-\mathrm{PknA}$ and 57-PknB. Resulting trajectories were captured at every 1 ps after which they were analyzed as data plots on the Microcal Origin software version 6.0 [58]. Also, snapshots were retrieved for both complexes and were analyzed for conformational variations and interaction dynamics using the UCSF Chimera version 1.11.2 GUI and Discovery Studio 2016 Client [59]. 


\subsection{Binding Energy Calculations and Decomposition of Per-Residue Energy}

The non-uniformity in the binding affinities of both analogs to PknA and PknB were determined using the Molecular Mechanics/Generalized Born Surface Area (MM/GBSA) method. This was achieved by estimating their binding energies profiles which incorporates all energy components involved in complex formation. To minimize entropical effects, we retrieved 1000 snapshots from the final $30 \mathrm{~ns}$ MD trajectories where the systems stabilized.

Binding energy calculations are represented mathematically as follows:

$$
\begin{gathered}
\Delta \mathrm{G}_{\text {bind }}=\mathrm{G}_{\text {complex }}-\left(\mathrm{G}_{\text {receptor }}+\mathrm{G}_{\text {inhibitor }}\right) \\
\Delta \mathrm{G}_{\text {bind }}=\Delta \mathrm{G}_{\text {gas }}+\Delta \mathrm{G}_{\text {sol }}-\mathrm{T} \Delta \mathrm{S}=\Delta \mathrm{H}-\mathrm{T} \Delta \mathrm{S} \\
\Delta \mathrm{G}_{\text {gas }}=\Delta \mathrm{E}_{\text {int }}+\Delta \mathrm{E}_{\text {ele }}+\Delta \mathrm{E}_{\mathrm{vdW}} \\
\Delta \mathrm{G}_{\text {sol }}=\Delta \mathrm{G}_{\text {ele } \text {,sol(GB) }}-\Delta \mathrm{G}_{\mathrm{np}, \text { sol }} \\
\Delta \mathrm{G}_{\mathrm{np}, \text { sol }}=\gamma \mathrm{SASA}+\beta
\end{gathered}
$$

From the above equations, the gas phase energy $\left(\Delta \mathrm{G}_{\text {gas }}\right)$ is defined by the summation of internal $\left(\Delta \mathrm{E}_{\text {int }}\right)$, electrostatic $\left(\Delta \mathrm{E}_{\text {ele }}\right)$ and van der Waals $\left(\Delta \mathrm{E}_{\mathrm{vdW}}\right)$ energies while the polar solvation $\left(\Delta \mathrm{G}_{\text {ele,sol }}\right)$ and non-polar contribution to solvation $\left(\Delta \mathrm{G}_{\mathrm{np}, \text { sol }}\right)$ terms define the solvation free energy, defined as $\Delta \mathrm{G}_{\mathrm{sol}}$. The Generalized Born (GB) model was solved with the MM/GBSA method to determine $\left(\Delta \mathrm{G}_{\text {ele,sol }}\right)$ while as shown in eqn. (5), $\Delta \mathrm{G}_{\mathrm{np} \text {,sol }}$ was solved by a linear relationship between the surface tension proportionality constant $(\gamma)$, solvent accessible surface area, SASA $\left(\AA^{2}\right)$, and $\beta$ which is also a constant. The value for $\gamma$ is set at $0.0072 \mathrm{kcal}\left(\mathrm{mol}^{-1} \AA^{-2}\right)$ while the linear incorporation of pairwise overlaps (LCPO) model is used for SASA estimations.

In addition, we performed per-residue energy decomposition to obtain significant insights into the dynamic roles and energy contributions of site residues of PknA and PknB towards ligand-receptor binding and stabilization.

\subsection{Analyses of Dynamic Cross-Correlation Matrix (DCCM)}

This method was used to investigate dynamical movements and fluctuations of PknA and PknB $\mathrm{C}-\alpha$ atoms in the presence of both compounds; 33 and 57 . This allows us to obtain structural insights into the time-correlated motions of residues within the protein systems over the simulation period, presented as a 3D matrix. DCCM is mathematically expressed as follows:

$$
\mathrm{C}_{\mathrm{ij}}=<\Delta \mathrm{r}_{\mathrm{i}} \times \Delta \mathrm{r}_{\mathrm{j}}>\div\left(<\mathrm{r}_{\mathrm{i}}^{2}><\Delta \mathrm{r}_{\mathrm{j}}^{2}>\right)^{1 / 2}
$$

From the equation, $\mathrm{C}_{\mathrm{ab}}$ depicts the mean positional displacement of the ath atom, with the angular brackets indicating the time average over the entire trajectory. a and $b$ represent the ath and bth atoms while their respective displacements are shown as $\Delta \mathrm{ra}$ and $\Delta \mathrm{rb}$. The cross-correlation function varied from -1 to 1 depictive of the directions of motions. A highly positive $C_{a b}$ value indicates motions that strongly correlated between residues a and $b$ (same direction) while a negative value for $C_{a b}$ shows that the direction of motion is anti-correlated. The CPPTRAJ module of Amber18 was used to obtain matrices from the trajectories which were plotted using the Origin analytical software version 6.0.

\subsection{Principal Component Analyses (PCA)}

We employed the PCA method to investigate changes in the ligand dynamics and conformations over the course of the simulation $[60,61]$ relative to their differential inhibitory activities. The PCA metrics constitute the eigenvalues and eigenvectors, which respectively describe the magnitude and direction of motions. The first two principal components (PC1 and PC2) were computed using 
the Amber18 CPPTRAJ module while the conformational behaviors of the simulated systems were projected along the direction of these two components (ev1/PC1 vs ev2/PC2).

\section{Conclusions}

The highly disparate dual binding activity of compound 33 compared 57 in Ser/Thr kinases; $\operatorname{PknA}\left(K_{i}:<8 \rightarrow>4000 \mathrm{nM}\right)$ and $\mathrm{PknB}\left(K_{i}:<1 \rightarrow>4000 \mathrm{nM}\right)$, as experimentally reported makes it imperative to investigate the underlying mechanisms. This explains the rationale of this study which was achieved using computational methods that entailed molecular dynamics simulations and MM/GBSA-based analysis of binding free energy. Our findings revealed that compared to 57, the binding of 33 stabilized the conformations of both proteins and reduced their structural activities. The impact of $\mathbf{3 3}$ was also prominent at the active pockets of the proteins where it reduced mobilities and enhanced compactness. Its effect at these regions could be due to complementary interactions with key residues, which could, in turn, enhance its optimal stability and positioning. 3D structural analyses of the binding pockets revealed that the primary conformations of the P-loop, catalytic loop, helix C and DFG motif were systematically altered by 33 in order to bind optimally.

The NBPs of PknA and B, on the other hand, were highly unstable in the presence of $\mathbf{5 7}$ with high $\mathrm{C} \alpha$ motions among constituent residues. Analysis of ligand mobility revealed that 33 was more stable in PknA and B with characteristic deep hydrophobic binding while 57 was highly unstable and more surface bound.

Furthermore, a similar pattern of bond formation was observed for 33 in both proteins, involving common (conserved and non-conserved) residues of their NBPs. Aromatic $(\pi)$, coupled with hydrogen interactions played crucial roles in the binding of 33, particularly GLY22 $(\rightarrow$ GLY20 PknB $)$, LYS42 $\left(\rightarrow\right.$ LYS40 $\left._{\text {PknB }}\right)$, GLU96 $\left(\rightarrow\right.$ GLU93 $\left.{ }_{\text {PknB }}\right)$, VAL98 $\left(\rightarrow\right.$ VAL95 $\left.{ }_{\text {PknB }}\right)$, LYS143 $\left(\rightarrow\right.$ LYS140 $\left._{\text {PknB }}\right)$, THR158 $\left(\rightarrow\right.$ MET155 $\left.{ }_{\text {PknB }}\right)$ and ASP159 $\left(\rightarrow\right.$ ASP156 $\left.{ }_{\text {pnB }}\right)$. The quinazoline ring, in addition to the thiophene and pyrazole rings of 33 was crucial to the formation of a high number of $\pi$ and $\mathrm{H}$ interactions. Likewise, the $\mathrm{Cl}$ substituent of $\mathbf{3 3}$ engendered interactions with the catalytic loop residue, LYS143; an interaction that was lost in the 57-bound complexes. These interactions culminated in high vdW and electrostatic energy contributions with $\Delta G_{\text {bind }}$ of compound 33 summing up to $-45.75 \mathrm{kcal} \mathrm{mol}^{-1}$ for PknA and $-50.0 \mathrm{kcal} \mathrm{mol}^{-1}$ for PknB. Unfavorable interactions were observed in the 57-PknA and B complexes, which could have repulsive effects on ligand positioning and stability. Consequently, binding free energy estimations revealed a notable decrease in $57-\Delta G_{b i n d}$ to $-20.9 \mathrm{kcal} \mathrm{mol}^{-1}(\mathrm{PknA})$ and $-20.03 \mathrm{kcal} \mathrm{mol}^{-1}(\mathrm{PknB})$. More so, polar solvation terms were highly unfavorable in $\mathbf{5 7}$ compared to 33 while vdW energetic contributions were pertinent to the dual binding and stability of compound 33. These findings, altogether, revealed the superior dual binding affinity of 33 over 57, and underlying mechanisms. Rational explanations from this study are expected to significantly aid the structure-based design of highly selective molecules with dual inhibitory activities towards Ser/Thr kinases; PknA and PknB.

Supplementary Materials: The following are available online, Figure S1: RMSD analyses of structural and NBP stability of (A) unbound PknA (black) and unbound PknB (red) (B) Comparative whole structure FE-RMSD (post-equilibrated) of unbound PknA and PknB (C) Comparative FE-RMSD analysis of unbound PknA and PknB nucleotide binding pocket (D) FE-RoG analysis of the degree of mobility (compactness) of unbound PknA and PknB. Figure S2: Hydrogen bond analyses of the simulated systems across the entire trajectory (A) unbound(black), 57- (green) and 33-bound (red) PknA (B) unbound-, 57- and 33-bound PknB. Inset is the estimation of average hydrogen bonds that occurred within each system over the entire trajectory. Figure S3: Post-equilibrated (FE) RMSF analyses of unbound PknA and PknB. Highlighted in (A,B) are regions that correspond to the P-loop, Helix C, Catalytic loop and DFG motif. (C) DCCM analysis of residual motions across the entire unbound PknA structure and (D) DCCM analysis for unbound PknB. Highlighted are motions within the catalytic components. Figure S4: Conformational variations of catalytic components in unbound PknA and PknB along the simulated trajectories. Table S1. Hydrogen bond occupancies $\geq 90 \%$ in the unbound PknA, unbound PknB, 33-PknA, 33-PknB, 57-PknA and 57-PknB.

Author Contributions: Conceptualization, F.A.O.; Methodology, F.A.O.; Writing-original draft preparation, F.A.O.; writing-review and editing, F.A.O. and M.E.S.; supervision, M.E.S. All authors have read and agreed to the published version of the manuscript. 
Funding: The research received no external funding.

Acknowledgments: Authors thank the College of Health Sciences, University of KwaZulu-Natal for infrastructural support and the Centre for High Performance Computing, Cape Town, South Africa for computational resources.

Conflicts of Interest: The authors declare no conflict of interest.

\section{References}

1. Khan, M.Z.; Kaur, P.; Nandicoori, V.K. Targeting the messengers: Serine/threonine protein kinases as potential targets for antimycobacterial drug development. IUBMB Life 2018. [CrossRef]

2. World Health Organization. Global Tuberculosis Report 2018; WHO: Geneva, Switzerland, 2018.

3. Sassetti, C.M.; Boyd, D.H.; Rubin, E.J. Genes required for mycobacterial growth defined by high density mutagenesis. Mol. Microbiol. 2003. [CrossRef] [PubMed]

4. Gupta, A.; Pal, S.K.; Pandey, D.; Fakir, N.A.; Rathod, S.; Sinha, D.; SivaKumar, S.; Sinha, P.; Periera, M.; Balgam, S.; et al. PknB remains an essential and a conserved target for drug development in susceptible and MDR strains of M. Tuberculosis. Ann. Clin. Microbiol. Antimicrob. 2017. [CrossRef] [PubMed]

5. Av-Gay, Y.; Everett, M. The eukaryotic-like Ser/Thr protein kinases of Mycobacterium tuberculosis. Trends Microbiol. 2000, 5, 238-244. [CrossRef]

6. Hanks, S.K.; Hunter, T. The eukaryotic protein kinase superfamily: Kinase (catalytic) domain structure and classification. FASEB J. 1995, 9, 576-596. [CrossRef] [PubMed]

7. Cole, S.T.; Brosch, R.; Parkhill, J.; Garnier, T.; Churcher, C.; Harris, D.; Gordon, S.V.; Eiglmeier, K.; Gas, S.; Barry, C.E.; et al. Deciphering the biology of mycobacterium tuberculosis from the complete genome sequence. Nature 1998, 393, 537-544. [CrossRef] [PubMed]

8. Sundar, S.; Thangamani, L.; Manivel, G.; Kumar, P.; Piramanayagam, S. Molecular docking, molecular dynamics and MM/PBSA studies of FDA approved drugs for protein kinase a of Mycobacterium tuberculosis; application insights of drug repurposing. Inform. Med. Unlocked 2019. [CrossRef]

9. Carette, X.; Platig, J.; Young, D.C.; Helmel, M.; Young, A.T.; Wang, Z.; Potluri, L.P.; Moody, C.S.; Zeng, J.; Prisic, S.; et al. Multisystem analysis of Mycobacterium tuberculosis reveals kinase-dependent remodeling of the pathogen-environment interface. MBio 2018. [CrossRef]

10. Kang, C.M.; Abbott, D.W.; Sang, T.P.; Dascher, C.C.; Cantley, L.C.; Husson, R.N. The Mycobacterium tuberculosis serine/threonine kinases PknA and PknB: Substrate identification and regulation of cell shape. Genes Dev. 2005. [CrossRef]

11. Shah, I.M.; Laaberki, M.H.; Popham, D.L.; Dworkin, J. A Eukaryotic-like Ser/Thr Kinase Signals Bacteria to Exit Dormancy in Response to Peptidoglycan Fragments. Cell 2008. [CrossRef]

12. Chawla, Y.; Upadhyay, S.; Khan, S.; Nagarajan, S.N.; Forti, F.; Nandicoori, V.K. Protein kinase B (PknB) of Mycobacterium tuberculosis is essential for growth of the pathogen in vitro as well as for survival within the host. J. Biol. Chem. 2014. [CrossRef] [PubMed]

13. Ortega, C.; Liao, R.; Anderson, L.N.; Rustad, T.; Ollodart, A.R.; Wright, A.T.; Sherman, D.R.; Grundner, C. Mycobacterium tuberculosis Ser/Thr Protein Kinase B Mediates an Oxygen-Dependent Replication Switch. PLoS Biol. 2014. [CrossRef] [PubMed]

14. Fernandez, P.; Saint-Joanis, B.; Barilone, N.; Jackson, M.; Gicquel, B.; Cole, S.T.; Alzari, P.M. The Ser/Thr protein kinase PknB is essential for sustaining mycobacterial growth. J. Bacteriol. 2006. [CrossRef] [PubMed]

15. Molle, V.; Kremer, L. Division and cell envelope regulation by Ser/Thr phosphorylation: Mycobacterium shows the way. Mol. Microbiol. 2010, 75, 1064-1077. [CrossRef] [PubMed]

16. Barthe, P.; Mukamolova, G.V.; Roumestand, C.; Cohen-Gonsaud, M. The structure of PknB extracellular PASTA domain from mycobacterium tuberculosis suggests a ligand-dependent kinase activation. Structure 2010. [CrossRef]

17. Gee, C.L.; Papavinasasundaram, K.G.; Blair, S.R.; Baer, C.E.; Falick, A.M.; King, D.S.; Griffin, J.E.; Venghatakrishnan, H.; Zukauskas, A.; Wei, J.R.; et al. A phosphorylated pseudokinase complex controls cell wall synthesis in mycobacteria. Sci. Signal. 2012. [CrossRef] 
18. Pereira, S.F.F.; Goss, L.; Dworkin, J. Eukaryote-Like Serine/Threonine Kinases and Phosphatases in Bacteria. Microbiol. Mol. Biol. Rev. 2011. [CrossRef]

19. Bellinzoni, M.; Wehenkel, A.M.; Durán, R.; Alzari, P.M. Novel mechanistic insights into physiological signaling pathways mediated by mycobacterial Ser/Thr protein kinases. Genes Immun. 2019, 20, 383-393. [CrossRef]

20. Prisic, S.; Dankwa, S.; Schwartz, D.; Chou, M.F.; Locasale, J.W.; Kang, C.M.; Bemis, G.; Church, G.M.; Steene, H.; Husson, R.N. Extensive phosphorylation with overlapping specificity by Mycobacterium tuberculosis serine/threonine protein kinases. Proc. Natl. Acad. Sci. USA 2010. [CrossRef]

21. Meeske, A.J.; Riley, E.P.; Robins, W.P.; Uehara, T.; Mekalanos, J.J.; Kahne, D.; Walker, S.; Kruse, A.C.; Bernhardt, T.G.; Rudner, D.Z. SEDS proteins are a widespread family of bacterial cell wall polymerases. Nature 2016. [CrossRef]

22. Narayan, A.; Sachdeva, P.; Sharma, K.; Saini, A.K.; Tyagi, A.K.; Singh, Y. Serine threonine protein kinases of mycobacterial genus: Phylogeny to function. Physiol. Genom. 2007. [CrossRef] [PubMed]

23. Young, T.A.; Delagoutte, B.; Endrizzi, J.A.; Falick, A.M.; Alber, T. Structure of Mycobacterium tuberculosis PknB supports a universal activation mechanism for Ser/Thr protein kinases. Nat. Struct. Biol. 2003. [CrossRef] [PubMed]

24. Dasgupta, A.; Datta, P.; Kundu, M.; Basu, J. The serine/threonine kinase PknB of Mycobacterium tuberculosis phosphorylates PBPA, a penicillin-binding protein required for cell division. Microbiology 2006. [CrossRef] [PubMed]

25. Gay, L.M.; Ng, H.L.; Alber, T. A Conserved Dimer and Global Conformational Changes in the Structure of apo-PknE Ser/Thr Protein Kinase from Mycobacterium tuberculosis. J. Mol. Biol. 2006. [CrossRef]

26. Wang, T.; Bemis, G.; Hanzelka, B.; Zuccola, H.; Wynn, M.; Moody, C.S.; Green, J.; Locher, C.; Liu, A.; Gao, H.; et al. Mtb PKNA/PKNB Dual Inhibition Provides Selectivity Advantages for Inhibitor Design to Minimize Host Kinase Interactions. ACS Med. Chem. Lett. 2017. [CrossRef]

27. Villarino, A.; Duran, R.; Wehenkel, A.; Fernandez, P.; England, P.; Brodin, P.; Cole, S.T.; Zimny-Arndt, U.; Jungblut, P.R.; Cerveñansky, C.; et al. Proteomic identification of M. tuberculosis protein kinase substrates: PknB recruits GarA, a FHA domain-containing protein, through activation loop-mediated interactions. J. Mol. Biol. 2005. [CrossRef]

28. Wehenkel, A.; Bellinzoni, M.; Graña, M.; Duran, R.; Villarino, A.; Fernandez, P.; Andre-Leroux, G.; England, P.; Takiff, H.; Cerveñansky, C.; et al. Mycobacterial Ser/Thr protein kinases and phosphatases: Physiological roles and therapeutic potential. Biochimica et Biophysica Acta Proteins Proteomics 2008, 1784, 193-202. [CrossRef]

29. Lombana, T.N.; Echols, N.; Good, M.C.; Thomsen, N.D.; Ng, H.L.; Greenstein, A.E.; Falick, A.M.; King, D.S.; Alber, T. Allosteric activation mechanism of the Mycobacterium tuberculosis receptor Ser/Thr protein Kinase, PknB. Structure 2010. [CrossRef]

30. Xu, M.; Yu, L.; Wan, B.; Yu, L.; Huang, Q. Predicting inactive conformations of protein kinases using active structures: Conformational selection of Type-II inhibitors. PLOS ONE 2011. [CrossRef]

31. Baer, C.E.; Iavarone, A.T.; Alber, T.; Sassetti, C.M. Biochemical and spatial coincidence in the provisional Ser/Thr protein kinase interaction network of Mycobacterium tuberculosis. J. Biol. Chem. 2014. [CrossRef]

32. Nagarajan, S.N.; Upadhyay, S.; Chawla, Y.; Khan, S.; Naz, S.; Subramanian, J.; Gandotra, S.; Nandicoori, V.K. Protein Kinase a (PknA) of Mycobacterium tuberculosis is independently activated and is critical for growth in vitro and survival of the pathogen in the host. J. Biol. Chem. 2015. [CrossRef] [PubMed]

33. Chao, J.; Wong, D.; Zheng, X.; Poirier, V.; Bach, H.; Hmama, Z.; Av-Gay, Y. Protein kinase and phosphatase signaling in Mycobacterium tuberculosis physiology and pathogenesis. Biochimica et Biophysica Acta Proteins Proteomics 2010, 1804, 620-627. [CrossRef] [PubMed]

34. Chapman, T.M.; Bouloc, N.; Buxton, R.S.; Chugh, J.; Lougheed, K.E.A.; Osborne, S.A.; Saxty, B.; Smerdon, S.J.; Taylor, D.L.; Whalley, D. Substituted aminopyrimidine protein kinase B (PknB) inhibitors show activity against Mycobacterium tuberculosis. Bioorganic Med. Chem. Lett. 2012. [CrossRef] [PubMed]

35. Nott, T.J.; Kelly, G.; Stach, L.; Li, J.; Westcott, S.; Patel, D.; Hunt, D.M.; Howell, S.; Buxton, R.S.; O’Hare, H.M.; et al. An intramolecular switch regulates phosphoindependent FHA domain interactions in Mycobacterium tuberculosis. Sci. Signal. 2009. [CrossRef]

36. Ventura, M.; Rieck, B.; Boldrin, F.; Degiacomi, G.; Bellinzoni, M.; Barilone, N.; Alzaidi, F.; Alzari, P.M.; Manganelli, R.; O'Hare, H.M. GarA is an essential regulator of metabolism in Mycobacterium tuberculosis. Mol. Microbiol. 2013. [CrossRef] 
37. Veyron-Churlet, R.; Zanella-Cléon, I.; Cohen-Gonsaud, M.; Molle, V.; Kremer, L. Phosphorylation of the Mycobacterium tuberculosis $\beta$-ketoacyl-acyl carrier protein reductase MabA regulates mycolic acid biosynthesis. J. Biol. Chem. 2010. [CrossRef]

38. Vilchèze, C.; Molle, V.; Carrère-Kremer, S.; Leiba, J.; Mourey, L.; Shenai, S.; Baronian, G.; Tufariello, J.; Hartman, T.; Veyron-Churlet, R.; et al. Phosphorylation of KasB Regulates Virulence and Acid-Fastness in Mycobacterium tuberculosis. PLoS Pathog. 2014. [CrossRef]

39. Székely, R.; Wáczek, F.; Szabadkai, I.; Németh, G.; Hegymegi-Barakonyi, B.; Eros, D.; Szokol, B.; Pató, J.; Hafenbradl, D.; Satchell, J.; et al. A novel drug discovery concept for tuberculosis: Inhibition of bacterial and host cell signalling. Immunol. Lett. 2008. [CrossRef]

40. Ortiz-Lombardía, M.; Pompeo, F.; Boitel, B.; Alzari, P.M. Crystal structure of the catalytic domain of the PknB serine/threonine kinase from Mycobacterium tuberculosis. J. Biol. Chem. 2003. [CrossRef]

41. Gupta, V.; Naqvi, A.; Tanwar, J.; Mishra, K. Molecular Modeling study of Protein Kinase PKnB from Mycobacterium tuberculosis with derivatives of 1,3,4- Thiadiazoles. Nat. Preced. 2011. [CrossRef]

42. Xu, J.; Wang, J.; Zhou, J.; Xu, C.; Huang, B.; Xing, Y.; Wang, B.; Luo, R.; Wang, Y.; You, X.; et al. A novel protein kinase inhibitor IMB-YH-8 with anti-tuberculosis activity. Sci. Rep. 2017. [CrossRef] [PubMed]

43. Williams, M.A.; Ladbury, J.E. Hydrogen bonds in protein-ligand complexes. In Protein-Ligand Interactions: From Molecular Recognition to Drug Design; Wiley-VCH: Weinheim, Germany, 2005; ISBN 9783527601813.

44. Majewski, M.; Ruiz-Carmona, S.; Barril, X. An investigation of structural stability in protein-ligand complexes reveals the balance between order and disorder. Commun. Chem. 2019. [CrossRef]

45. Menéndez, C.A.; Accordino, S.R.; Gerbino, D.C.; Appignanesi, G.A. Hydrogen bond dynamic propensity studies for protein binding and drug design. PLOS ONE 2016. [CrossRef] [PubMed]

46. Prisic, S.; Husson, R.N. Mycobacterium tuberculosis Serine/Threonine Protein Kinases. Microbiol. Spectr. 2014. [CrossRef]

47. Alber, T. Signaling mechanisms of the Mycobacterium tuberculosis receptor Ser/Thr protein kinases. Curr. Opin. Struct. Biol. 2009, 19, 650-657. [CrossRef]

48. Lobanov, M.Y.; Bogatyreva, N.S.; Galziskaya, O. Radius of gyration as an indicator of protein structure compactness. Mol. Biol. 2008, 42, 623-628. [CrossRef]

49. Olotu, F.A.; Munsamy, G.; Soliman, M.E.S. Does Size Really Matter? Probing the Efficacy of Structural Reduction in the Optimization of Bioderived Compounds-A Computational "Proof-of-Concept". Comput. Struct. Biotechnol. J. 2018, 16, 573-586. [CrossRef]

50. Jiang, Y.; Li, L.; Zhang, H.; Feng, W.; Tan, T. Lid closure mechanism of Yarrowia lipolytica lipase in methanol investigated by molecular dynamics simulation. J. Chem. Inf. Model. 2014. [CrossRef]

51. Singh, S.K.; Das, A. The $\mathrm{n} \rightarrow \pi^{*}$ interaction: A rapidly emerging non-covalent interaction. Phys. Chem. Chem. Phys. 2015. [CrossRef]

52. Olotu, F.A.; Soliman, M.E.S. From mutational inactivation to aberrant gain-of-function: Unraveling the structural basis of mutant p53 oncogenic transition. J. Cell. Biochem. 2018, 119. [CrossRef]

53. Akher, F.B.; Farrokhzadeh, A.; Olotu, F.A.; Agoni, C.; Soliman, M.E.S. The irony of chirality-unveiling the distinct mechanistic binding and activities of 1-(3-(4-amino-5-(7-methoxy-5-methylbenzo [b] thiophen-2-yl)-7 H-pyrrolo [2, 3-d] pyrimidin-7-yl) pyrrolidin-1-yl) prop-2-en-1-one enantiomers as irreversible covalent FGFR4 inhibitors. Org. Biomol. Chem. 2019, 17, 1176-1190. [CrossRef]

54. Frisch, M.J.G.; Trucks, W.; Schlegel, H.B.; Scuseria, G.E.; Robb, M.A.; Cheeseman, J.R.; Scalmani, G.; Barone, V.; Mennucci, B.; Petersson, G.A.; et al. Gaussian, 16; Scientific Research Publisher: Wuhan, China, 2016.

55. Case, D.A. Amber 18; University of California: San Francisco, CA, USA, 2018.

56. Hess, B.; Bekker, H.; Berendsen, H.J.C.; Fraaije, J.G.E.M. LINCS: A Linear Constraint Solver for molecular simulations. J. Comput. Chem. 1997, 18, 1463-1472. [CrossRef]

57. Berendsen, H.J.C.; Postma, J.P.M.; van Gunsteren, W.F.; DiNola, A.; Haak, J.R. Molecular dynamics with coupling to an external bath. J. Chem. Phys. 1984, 81, 3684-3690. [CrossRef]

58. Seifert, E. OriginPro 9.1: Scientific Data Analysis and Graphing Software-Software Review. J. Chem. Inf. Model. 2014, 54, 1552. [CrossRef] [PubMed]

59. Biovia, D.S. Discovery Studio 2016 Client; San Diego Dassault Systèmes: San Diego, CA, USA, 2016. 
60. Sittel, F.; Jain, A.; Stock, G. Principal component analysis of molecular dynamics: On the use of Cartesian vs. internal coordinates. J. Chem. Phys. 2014, 141. [CrossRef] [PubMed]

61. Wolf, A.; Kirschner, K.N. Principal component and clustering analysis on molecular dynamics data of the ribosomal L11 23S subdomain. J. Mol. Model. 2013, 19, 539-549. [CrossRef]

Sample Availability: Samples of the compounds are not available from the authors.

(C) 2020 by the authors. Licensee MDPI, Basel, Switzerland. This article is an open access article distributed under the terms and conditions of the Creative Commons Attribution (CC BY) license (http://creativecommons.org/licenses/by/4.0/). 